\title{
Human chronic myeloid leukemia stem cells are insensitive to imatinib despite inhibition of BCR-ABL activity
}

\author{
Amie S. Corbin,,$^{1,2}$ Anupriya Agarwal, ${ }^{1}$ Marc Loriaux, ${ }^{1,3}$ Jorge Cortes, ${ }^{4}$ \\ Michael W. Deininger, ${ }^{1}$ and Brian J. Druker ${ }^{1,2}$

\begin{abstract}
1Division of Hematology and Medical Oncology, Oregon Health and Science University Cancer Institute, Portland, Oregon, USA ${ }^{2}$ Howard Hughes Medical Institute, Portland, Oregon, USA. ${ }^{3}$ Department of Pathology, Oregon Health and Science University,
\end{abstract} \\ Portland, Oregon, USA. ${ }^{4}$ M.D. Anderson Cancer Center, University of Texas, Houston, Texas, USA.
}

\begin{abstract}
Imatinib therapy, which targets the oncogene product BCR-ABL, has transformed chronic myeloid leukemia (CML) from a life-threatening disease into a chronic condition. Most patients, however, harbor residual leukemia cells, and disease recurrence usually occurs when imatinib is discontinued. Although various mechanisms to explain leukemia cell persistence have been proposed, the critical question from a therapeutic standpoint - whether disease persistence is BCR-ABL dependent or independent - has not been answered. Here, we report that human CML stem cells do not depend on BCR-ABL activity for survival and are thus not eliminated by imatinib therapy. Imatinib inhibited BCR-ABL activity to the same degree in all stem $\left(\mathrm{CD}^{+} 4^{+} \mathrm{CD}^{-} 8^{-}, \mathrm{CD} 33^{+}\right)$and progenitor $\left(\mathrm{CD}^{+} 4^{+} \mathrm{CD}^{+} 8^{+}\right)$cells and in quiescent and cycling progenitors from newly diagnosed CML patients. Although short-term in vitro imatinib treatment reduced the expansion of CML stem/progenitors, cytokine support permitted growth and survival in the absence of BCR-ABL activity that was comparable to that of normal stem/progenitor counterparts. Our findings suggest that primitive CML cells are not oncogene addicted and that therapies that biochemically target BCR-ABL will not eliminate CML stem cells.
\end{abstract}

\section{Introduction}

Chronic myeloid leukemia (CML) originates in a HSC with the reciprocal translocation $\mathrm{t}(9 ; 22)(1)$. The resulting Philadelphia chromosome $(\mathrm{Ph})$ produces $\mathrm{BCR}-\mathrm{ABL}$, a constitutively active tyrosine kinase that drives expansion of leukemic progeny (1). Targeted therapy with the ABL kinase inhibitor imatinib (Gleevec; Novartis) induces complete cytogenetic responses (CCRs) in more than $80 \%$ of newly diagnosed patients in the chronic phase (2). Most patients achieving CCRs, however, have $B C R-A B L$ transcripts detectable by RT-PCR (3). Those whose disease is undetectable by RT-PCR usually experience recurrence of active leukemia when imatinib therapy is discontinued $(4,5)$, which indicates that leukemic cells persist in most patients even when the disease burden is reduced below detectable limits. Therefore, the current recommendation is lifelong continuance of therapy, at considerable cost and sometimes despite significant side effects. Additionally, although the annual rate of relapse has declined over time (2), isolated patients have progressed from complete molecular response to blast crisis. The observation that minimal residual disease may persist for prolonged periods of time argues that the imatinib-resistant cell populations must contain leukemic stem cells with self-renewal capacity. Consistent with this, $\mathrm{CD}^{3} 4^{+}$progenitor cells from CCR patients contain $B C R-A B L$-positive cells, and leukemic stem cells were identified in patients achieving CCR

Authorship note: Amie S. Corbin and Anupriya Agarwal, as well as Michael W. Deininger and Brian J. Druker, contributed equally to this work.

Conflict of interest: B.J. Druker declares financial interest in MolecularMD and serves as a consultant for Roche and Nodality. M.W. Deininger receives research support from Bristol-Myers Squibb. J. Cortes receives research support from Novartis, Bristol-Myers Squibb, and Pfizer/Wyeth.

Citation for this article: J Clin Invest. 2011;121(1):396-409. doi:10.1172/JCI35721.
(6). Understanding the mechanisms by which primitive leukemic cells survive imatinib therapy will be critical to devising strategies aimed at their elimination.

Various mechanisms have been proposed to explain disease persistence. Alterations affecting BCR-ABL similar to those leading to acquired resistance could desensitize BCR-ABL to imatinib. For example, CML progenitor cells from some patients with CCR harbor imatinib-resistant BCR-ABL kinase domain mutants (7), and primitive CML cells demonstrate enhanced BCR-ABL expression (8). The correlation between these findings and the persistence of residual disease, however, is still controversial (9). Enhanced expression of the drug efflux pumps breast cancer resistance protein (10) and P-glycoprotein (11) in CML stem cells may reduce sensitivity to imatinib by lowering intracellular imatinib concentrations (12-15). Conversely, efficient imatinib uptake by leukemic stem cells may require expression of human organic cation transporter $1(8,16,17)$. In vitro culture of primitive CML cells in the presence of imatinib leads to accumulation of quiescent cells. As a phenotypically similar population of cells from newly diagnosed patients can serially engraft immunodeficient mice, these cells may represent persistent leukemia cells in imatinib-treated patients; however, this has not been demonstrated experimentally $(18,19)$. It is also unclear whether the property of quiescence directs resistance or is an epiphenomenon not causally related to resistance. Finally, bone marrow microenvironment-derived signals may also protect leukemic stem cells from the effects of imatinib (20).

To date, the majority of studies of disease persistence focused on specific properties of CML stem cells that could mediate imatinib resistance $(7,8,19,21)$. While this approach has contributed valuable information about the nature of CML stem cells, it has neither provided evidence for a causative role of these properties in disease 
persistence nor guided strategies to overcome persistence. Conceptually, potential mechanisms of disease persistence can be classified into 2 general categories: (a) those in which BCR-ABL remains central to leukemia cell survival, but is not susceptible to imatinib inhibition within the context of a stem cell; and (b) those in which leukemic stem cell survival is independent of BCR-ABL activity. The ability of BCR-ABL-targeted therapy to eradicate CML will depend on this fundamental distinction. Addressing this central question should provide a rationale for investigating specific BCR$\mathrm{ABL}-$ dependent or -independent mechanisms of resistance and ultimately direct strategies to treat persistence, much in the way that the discovery of BCR-ABL reactivation in imatinib-resistant patients led to identification of kinase domain mutations and the development of second-line BCR-ABL inhibitor therapy (22-24).

In the present study, we evaluated the capacity of imatinib to inhibit BCR-ABL activity in immunophenotypically defined stem and progenitor cells and in quiescent and cycling progenitors. We additionally investigated how inhibition of BCR-ABL activity by imatinib and second-line BCR-ABL inhibitors affected survival of CML stem and progenitor cells with the aim of establishing whether BCR-ABL is a viable biochemical target in cell populations associated with disease persistence.

\section{Results}

Imatinib inhibits BCR-ABL in CML stem and progenitor cells. CML $\mathrm{CD} 34^{+}$progenitor cells are sensitive to imatinib inhibition; however, the activity and imatinib sensitivity of BCR-ABL in more primitive cell types remains controversial (25-27). Several reports have suggested that certain features of primitive CML cells should reduce sensitivity to imatinib, such as increased expression of BCR-ABL and increased expression of drug efflux pumps (8). Therefore, in a first series of experiments, we determined whether immature cell subtypes, as defined by immunophenotype, were equally sensitive to BCR-ABL inhibition by imatinib as their more mature counterparts. We initially used intracellular FACS analysis to examine total cellular phosphotyrosine levels in $\mathrm{Lin}^{-}$cells from newly diagnosed CML patients and normal bone marrow donors. Untreated cells were compared with those treated for 4 hours with $5 \mu \mathrm{M}$ imatinib in serum/cytokine-free conditions. Cells were costained with anti-CD34, -CD38, and -CD133 antibodies to define stem and progenitor cell subpopulations. $\mathrm{CD} 34^{+} \mathrm{CD} 38^{-}$and $\mathrm{CD}_{133^{+}}$cell populations contain the majority of stem cell activity, whereas $\mathrm{CD} 34^{+} \mathrm{CD} 38^{+}$cells represent multipotent committed progenitors, as shown previously by long-term culture initiating cell (LTC-IC) and murine long-term engraftment assays $(28,29)$. As expected, $\mathrm{CD}_{34}{ }^{+} \mathrm{CD} 38^{+}$cells showed a 3 -fold increase in phosphotyrosine MFI relative to isotype control that was reduced by imatinib treatment (Figure $1 \mathrm{~A}$ ). $\mathrm{CD} 34^{+} \mathrm{CD} 38^{-}$and $\mathrm{CD} 133^{+}$cells, which are enriched for stem cells, also demonstrated cytokineindependent induction of phosphotyrosine that was reduced by imatinib treatment (Figure 1A). Although imatinib treatment did not completely restore the MFI to the level of the isotype control, signals in imatinib-treated cells were identical to those of phenotypically matched normal cells exposed to imatinib $\left(\mathrm{CD} 34^{+} \mathrm{CD} 38^{+}\right.$, $P=0.3$; CD34 ${ }^{+} \mathrm{CD}_{38}{ }^{-}, P=0.1 ; \mathrm{CD} 133^{+}, P=0.2$; Student's $t$ test). This is consistent with suppression of BCR-ABL-dependent phosphotyrosine, the residual signal reflecting background. To confirm this assumption, we compared the phosphotyrosine FACS signal of imatinib-treated CML stem and progenitor cells to that of 3 imatinib-sensitive BCR-ABL-expressing cell lines. Following $5 \mu \mathrm{M}$ imatinib treatment, primary CML cell subtypes and all 3 cell lines showed identical residual phosphotyrosine FACS signals above isotype (Figure 1B). Additionally, phosphotyrosine immunoblots of the 3 cell lines demonstrated comparable phosphotyrosine suppression and residual signal following imatinib treatment, as determined by densitometric comparison with untreated cellular lysates (Figure 1B). This indicates that the residual signal observed in the FACS assay is caused by BCR-ABL-independent cellular phosphorylation. Alternatively, complete suppression of BCR-ABL with imatinib may not be achievable either in cell lines or in primary cells. Importantly, however, the degree of BCR-ABL inhibition by imatinib in CML stem and progenitor cells was equivalent to that previously shown to block proliferation and induce apoptosis in CML-derived cell lines (30).

Although a high imatinib concentration suppressed BCR-ABL activity in both stem and progenitor cell compartments, we reasoned that more subtle differences in imatinib sensitivity between stem and progenitor cell types could contribute to stem cell persistence. We compared the inhibition of cellular phosphorylation in $\mathrm{CD} 34^{+} \mathrm{CD} 38^{-}$and $\mathrm{CD} 4^{+} \mathrm{CD} 38^{+}$cells from 3 newly diagnosed $\mathrm{CML}$ patients over a range of imatinib concentrations. Imatinib concentrations in excess of $5 \mu \mathrm{M}$ did not further reduce the phosphotyrosine signal in either cell type (Figure 1C), which indicates that our initial experiments were performed at saturating imatinib concentrations that achieved complete suppression of BCR-ABL. At lower imatinib concentrations, we observed a dose-dependent reduction in phosphotyrosine signal. Importantly, over a broad range of imatinib concentrations, the degree of BCR-ABL inhibition was the same in phenotypically defined stem and progenitor cells (Figure 1C). As it is not practical to experimentally mimic in vitro the fluctuations of imatinib concentrations that occur in the plasma of patients, we decided to use $5 \mu \mathrm{M}$ of imatinib in subsequent experiments. This is based on the fact that peak plasma concentrations achieved in vivo are above $5 \mu \mathrm{M}$, and that recent in vitro data suggest that the cellular response to imatinib is at least partially dependent on peak drug concentrations (31-34). Our observation of equivalent suppression of BCR-ABL activity in stem and progenitor cells at saturating and lower imatinib concentrations indicated that neither compromised target accessibility nor target modification within the stem cell population profoundly affects imatinib inhibition of BCR-ABL.

Total phosphotyrosine levels are a general indicator of cell signaling and may not specifically correlate with BCR-ABL activity. We therefore examined the phosphorylation status of the BCR-ABLspecific substrate CRK-like protein (CRKL) in $\mathrm{CD} 34^{+} \mathrm{CD} 38^{-}$stem cells and $\mathrm{CD} 34^{+} \mathrm{CD} 38^{+}$progenitor cells. Previous studies had suggested that phospho-CRKL levels, as analyzed by intracellular flow cytometry, were impervious to imatinib in the most primitive cell types $(27,35)$. We initially attempted to use flow cytometry to analyze phospho-CRKL levels and were able to identify a reproducible phospho-CRKL signal in cell lines that was suppressed by the addition of imatinib. In the context of primary CML CD34+ cells, however, we could not replicate using phospho-CRKL FACS the pattern of phospho-CRKL activation and imatinib inhibition observed in immunoblots (Supplemental Figure 1; supplemental material available online with this article; doi:10.1172/JCI35721DS1). Although we are not sure of the reason for this discrepancy, it is possible that the phospho-CRKL antibody cross-reacts with a nonspecific target in the context of primary CML cells. We therefore favored the use of phospho- 
A
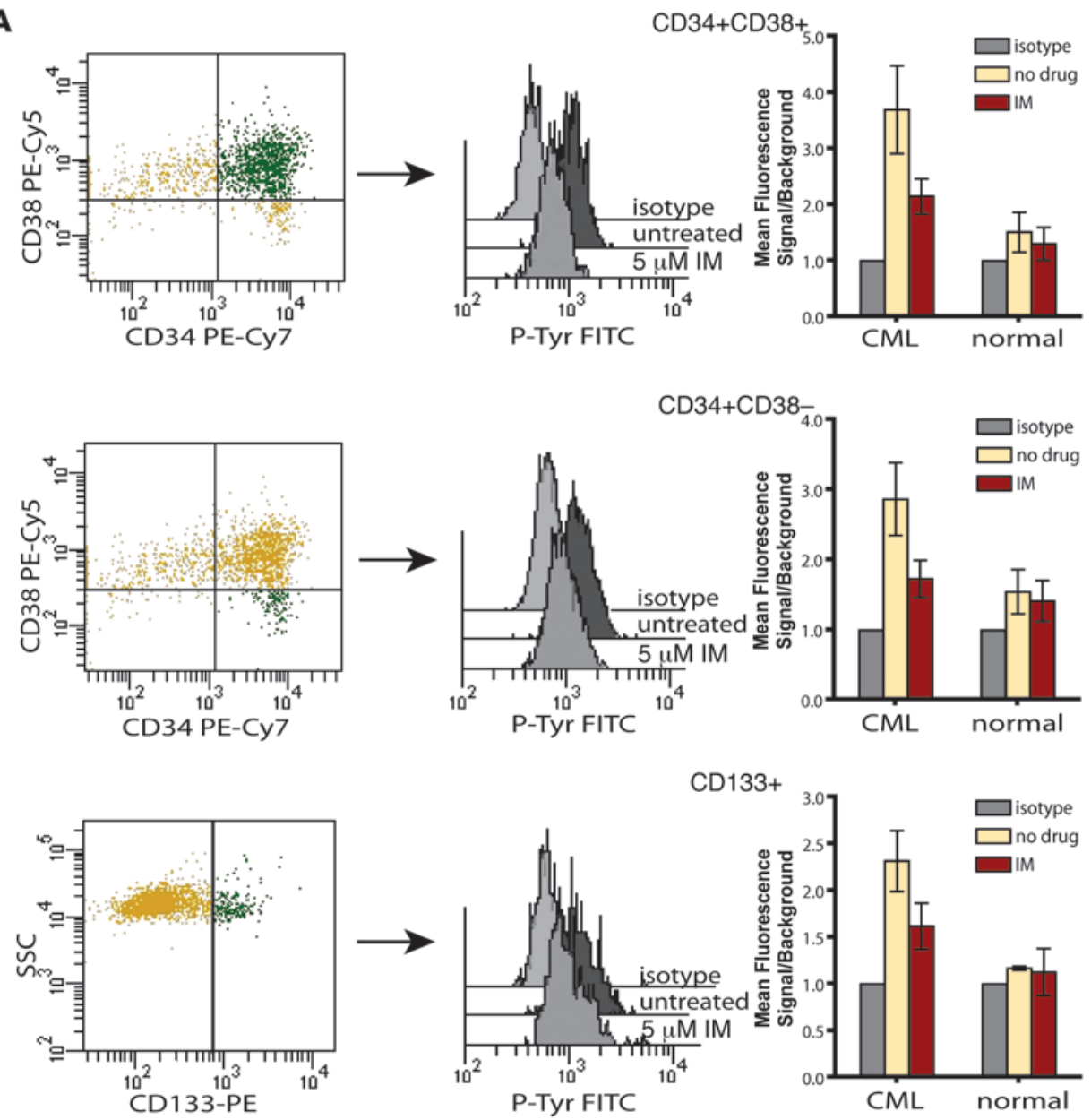

CD133+
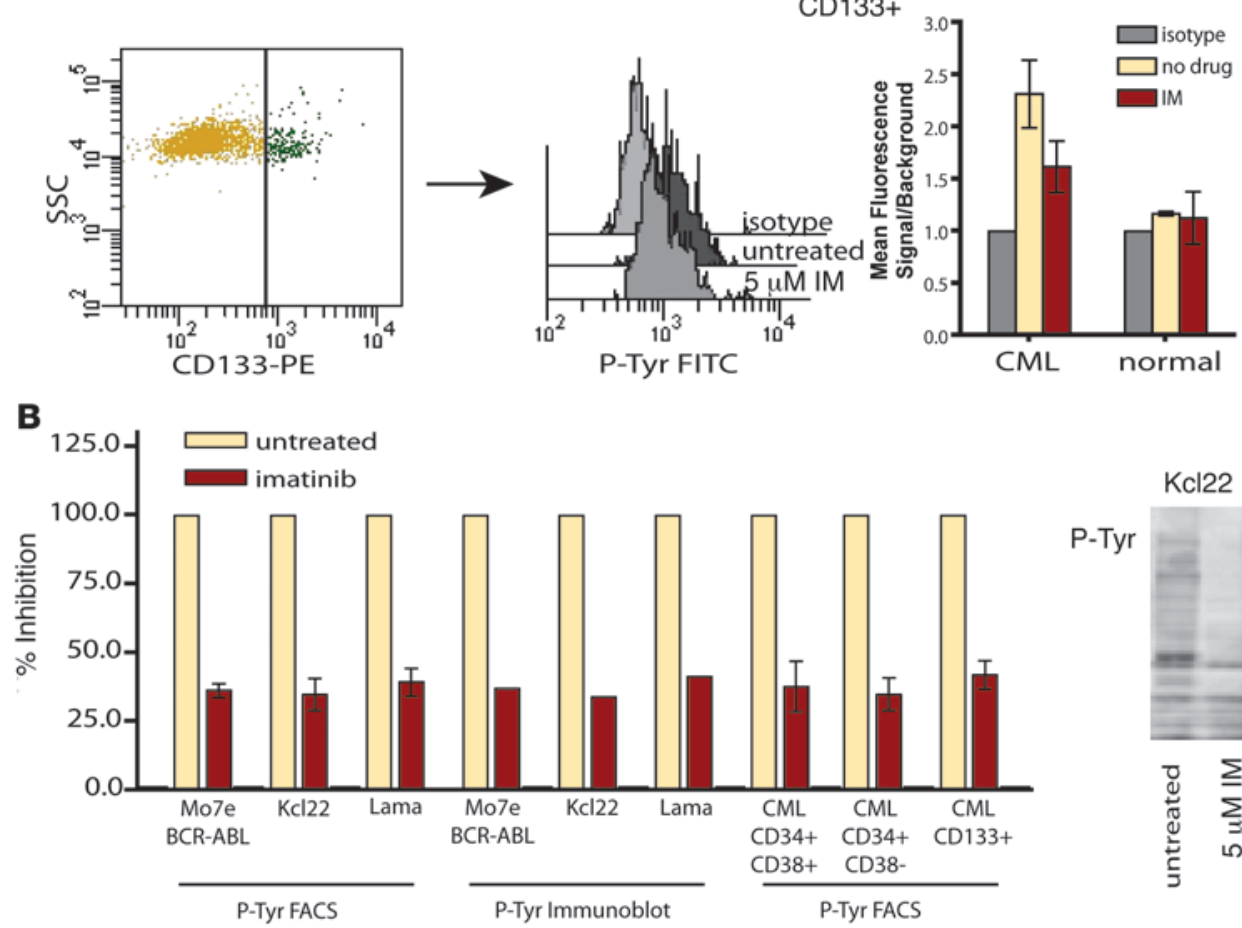
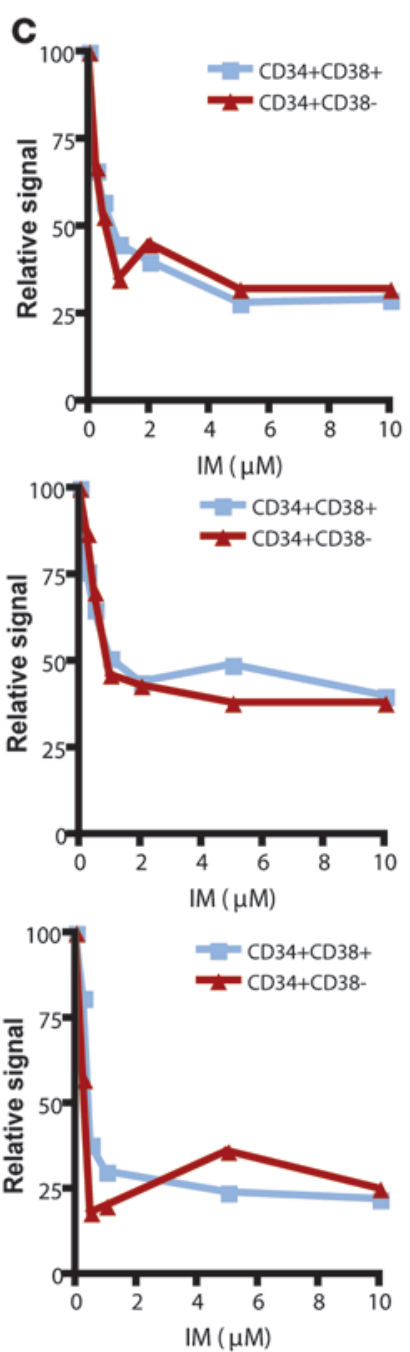

Figure 1

Inhibition of phosphotyrosine by imatinib in CML stem and progenitor cells. (A) Intracellular phosphotyrosine levels were evaluated by FACS in Lin- CML cells costained for CD34, CD38, and CD133. Representative phosphotyrosine histograms are shown in CML committed progenitor $\left(\mathrm{CD}_{34}{ }^{+} \mathrm{CD} 38^{+}\right)$and stem cell $\left(\mathrm{CD} 34^{+} \mathrm{CD} 38^{-}\right.$and $\left.\mathrm{CD} 133^{+}\right)$populations treated for 4 hours with or without $5 \mu \mathrm{M}$ imatinib $(\mathrm{IM})$. FACS data are displayed on a logarithmic scale. Background signal was established in the same populations by staining with a matched isotype control. $\mathrm{MFI} \pm \mathrm{SEM}$ for phosphotyrosine signal of treated and untreated cells relative to isotype are shown ( $n=10$ [CML]; 3 [normal]). (B) Suppression of phosphotyrosine FACS signal by imatinib in primary CML stem and progenitor cell populations was compared with 3 BCR-ABL-expressing cell lines. Signal over isotype is shown as percent of untreated. A representative phosphotyrosine immunoblot is shown for the leukemic cell line Kcl22 treated or not with $5 \mu \mathrm{M}$ imatinib. (C) Dose-dependent inhibition of BCR-ABL activity by imatinib in CD34+CD38+ and CD34+CD38- cells was evaluated by phosphotyrosine FACS in 3 independent CML samples. Signals are graphed as percent of untreated. 
A

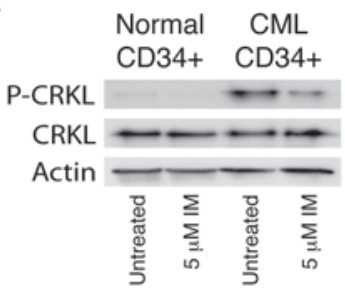

B
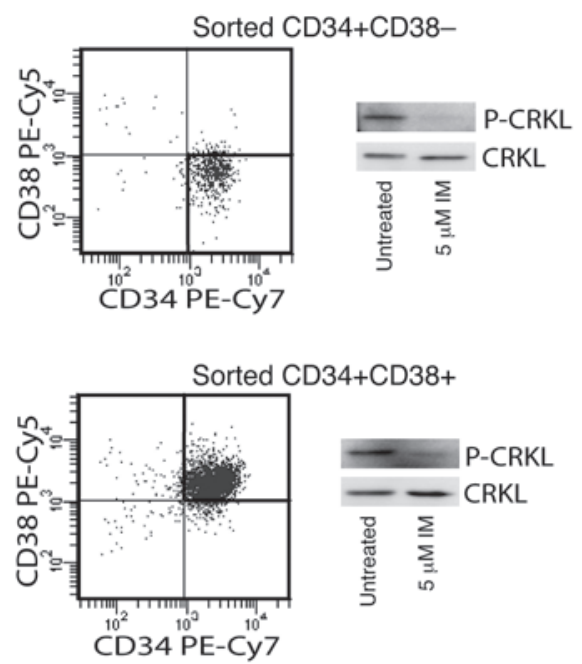

CML-2

Sorted CD34+CD38-
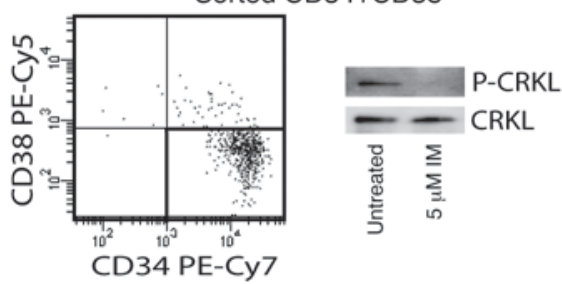
- CRKL ఫ

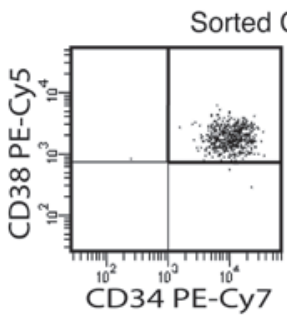

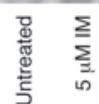

C

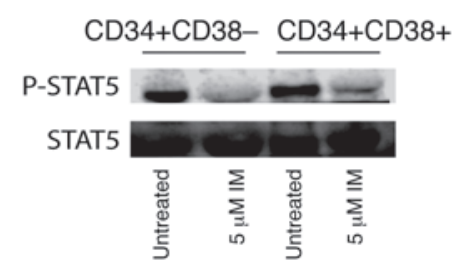

D

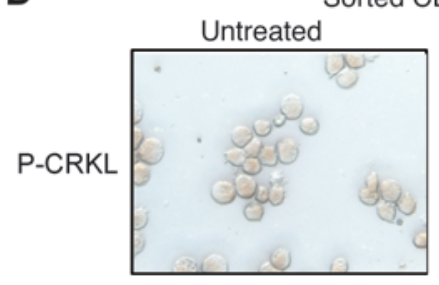

Sorted CD34+CD38-
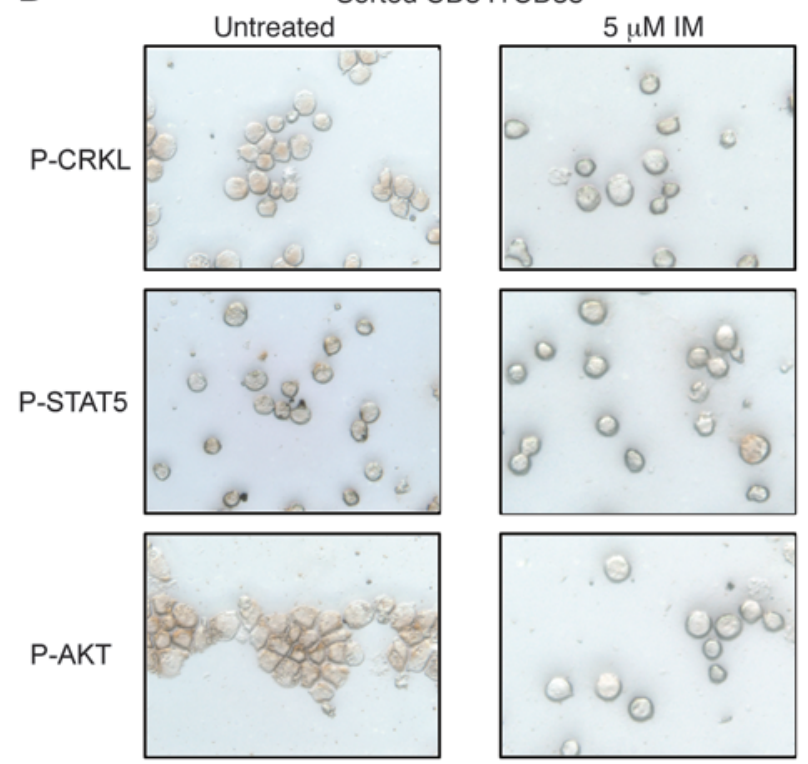

Sorted CD34+CD38+
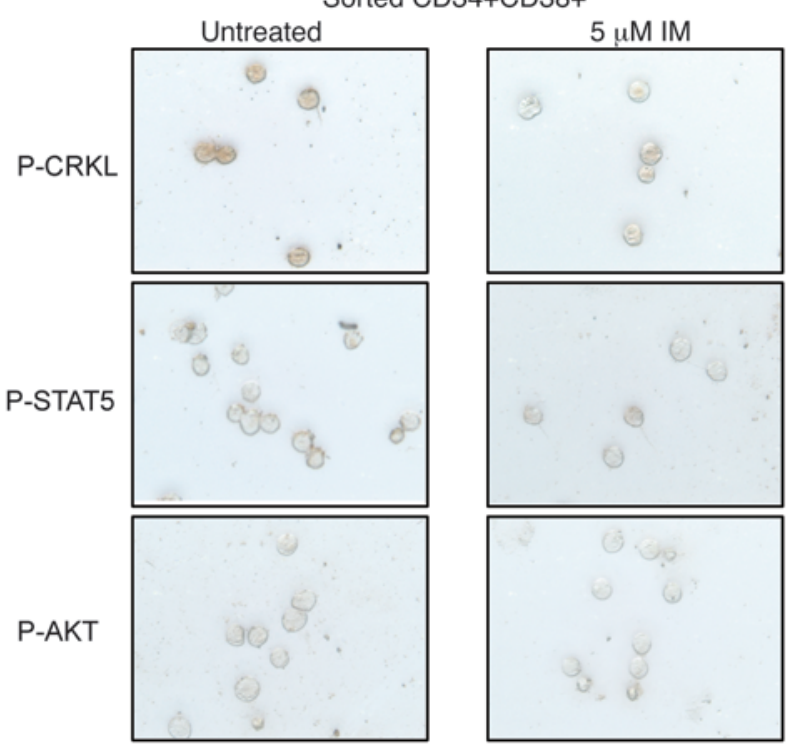

Figure 2

Inhibition of phospho-CRKL by imatinib in CML stem and progenitor cells. (A) Phospho-CRKL levels in normal CD34+ cells were compared with CML CD34+ cells treated or not with imatinib. Total CRKL and actin are shown as loading controls. (B) Phospho-CRKL and (C) phospho-STAT5 immunoblots with lysate from sorted $\mathrm{CD} 34^{+} \mathrm{CD} 38^{+}$and $\mathrm{CD} 34^{+} \mathrm{CD} 38^{-} \mathrm{CML}$ cells treated 4 hours with or without $5 \mu \mathrm{M}$ imatinib demonstrated inhibition of BCR-ABL by imatinib in both populations. Total CRKL and total STAT5 are shown as respective loading controls. (D) Phospho-CRKL, phospho-STAT5, and phospho-AKT immunocytochemical stains of sorted CD34+CD38- and CD34+CD38+ CML cells treated 4 hours with or without $5 \mu \mathrm{M}$ imatinib demonstrated BCR-ABL inhibition in all cells within the population. Representative cells are shown. Identical data were obtained for a second sample (not shown). 
A

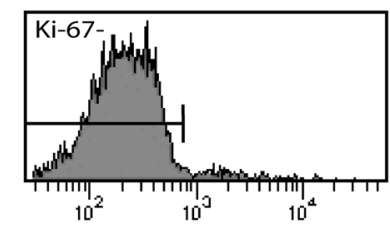

Ki-67 PE

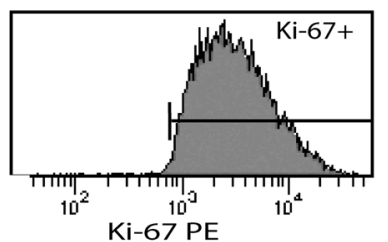

Ki-67 PE

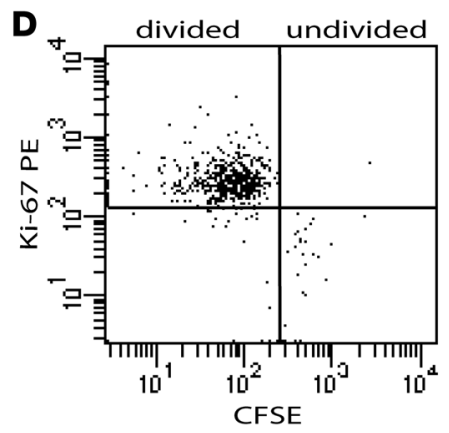

B

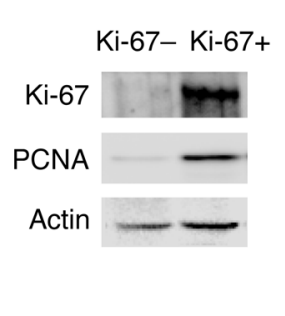

E

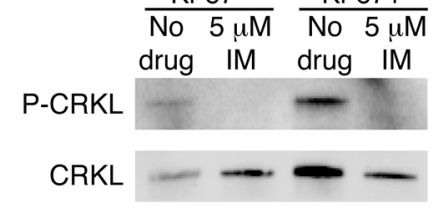

P-CRKL

CRKL
Sorted CML \#2

$\mathrm{Ki}-67-\mathrm{Ki}-67+$

No $5 \mu \mathrm{M}$ No $5 \mu \mathrm{M}$

drug IM drug IM

C

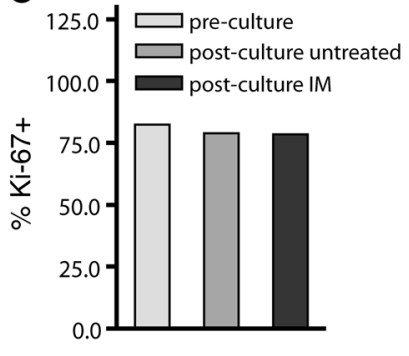

Sorted CML \#1 Ki-67- $\mathrm{Ki}-67+$

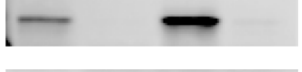

Figure 3

Inhibition of phospho-CRKL by imatinib in quiescent and cycling CML cells. (A) Lin-Ki-67and $\mathrm{Lin}-\mathrm{Ki}-67+\mathrm{CML}$ cells were FACS sorted into quiescent and cycling fractions, respectively. Representative histograms are shown. (B) Immunoblots of Ki-67 and PCNA in sorted Lin-Ki-67- and Lin-Ki-67+ CML cells were used to confirm sort purity, as indicated by exclusive expression of these proteins in the cycling fraction. Representative blots are shown. Actin is included as a loading control. (C) Ki-67 expression was evaluated by FACS prior to and following 4-hour culture with or without $5 \mu \mathrm{M}$ imatinib. (D) Lin- cells stained with CFSE and cultured for 72 hours with $5 \mu \mathrm{M}$ imatinib were analyzed for Ki-67 expression. Ki-67 expression is shown in undivided (CFSEhi) cells and in cells having undergone 1 or more divisions (CFSE ${ }^{1 / \mathrm{mod}}$ ). (E) PhosphoCRKL immunoblots of quiescent versus cycling cells treated 4 hours with or without imatinib are shown for 2 newly diagnosed CML samples. Total CRKL is included as a loading control.
CRKL immunoblot analysis on FACS-sorted stem and progenitor cell populations when sufficient cell numbers were available. To confirm that the detection of phospho-CRKL corresponds with BCR-ABL activity, we immunoblotted normal and CML CD34+ cell lysates following 4-hour treatment with imatinib. PhosphoCRKL signal in normal cells was weak compared with untreated $\mathrm{CML} \mathrm{CD} 34^{+}$cells and was not additionally reduced by imatinib treatment (Figure 2A). Imatinib treatment eliminated the majority $(75 \%)$ of phospho-CRKL signal in CD $34^{+}$CML cells; however, normal levels were not restored, which indicates that there may be some residual BCR-ABL activity or BCR-ABL-independent, but CML-specific, CRKL phosphorylation. Nonetheless, the majority of phospho-CRKL signal in CML cells appeared to be BCR-ABL dependent. We evaluated the phospho-CRKL signal in sorted $\mathrm{CD} 34^{+} \mathrm{CD} 38^{+}$and $\mathrm{CD} 34^{+} \mathrm{CD} 38^{-} \mathrm{CML}$ cells. Consistent with the results observed for total cellular phosphorylation, $5 \mu \mathrm{M}$ imatinib equivalently inhibited CRKL phosphorylation in both populations (Figure 2B). To further support our findings that BCR-ABL activity was inhibited by imatinib in both cell populations, we additionally evaluated the phosphorylation of the BCR-ABL substrate STAT5 by immunoblot. As with CRKL, STAT5 phosphorylation was inhibited by imatinib in both cell populations (Figure 2C). We conclude from the results of the complementary phosphotyrosine FACS assay, phospho-CRKL immunoblots, and phospho-STAT5 immunoblots that imatinib suppresses the majority of BCR-ABL kinase activity in both stem and progenitor cell populations.

Although phenotypic markers are widely used to define populations with enriched stem cell activity, it is likely that there is still functional heterogeneity within these populations. It is therefore possible that subpopulations within the stem cell compartment (as defined by $\mathrm{CD} 4^{+} \mathrm{CD} 38^{-}$markers) could behave differently from the population as a whole with regard to BCR-ABL activity and inhi- bition by imatinib. To address this possibility, we analyzed CRKL, STAT5, and AKT phosphorylation by immunocytochemistry in sorted $\mathrm{CD} 34^{+} \mathrm{CD} 38^{+}$and $\mathrm{CD} 34^{+} \mathrm{CD} 38^{-}$cells that were untreated or treated with $5 \mu \mathrm{M}$ imatinib. BCR-ABL activity was present in all cells in the $\mathrm{CD} 34^{+} \mathrm{CD} 38^{+}$compartment. Single cells lacking BCR-ABL activity were observed infrequently in the CD $34^{+} \mathrm{CD} 38^{-}$ compartment, and these likely represent nonleukemic stem cells. Consistent with the behavior of the population as a whole, imatinib suppressed phospho-CRKL and phospho-STAT5 in all individual cells within both populations (Figure 2D). In contrast to phospho-CRKL and phospho-STAT5, which were easily detectable in $\mathrm{CD} 34^{+} \mathrm{CD} 38^{+}$and $\mathrm{CD} 34^{+} \mathrm{CD} 38^{-}$cells, phospho-AKT (Ser473) staining was weak in $\mathrm{CD} 34^{+} \mathrm{CD} 38^{-}$compared with $\mathrm{CD} 34^{+} \mathrm{CD} 38^{+}$ cells, and little change was observed upon treatment with imatinib (Figure 2D). Interestingly, a recent report demonstrated nuclear localization of FOXO3a in primitive CML cells despite the presence of active BCR-ABL (36). Since AKT phosphorylation of FOXO transcription factors leads to their retention in the cytoplasm, this finding suggests that AKT may not be active in this most primitive population, which in turn is consistent with our results. Together, our findings argue that imatinib uniformly inhibits BCR-ABL signaling within the $\mathrm{CD} 34^{+} \mathrm{CD} 38^{-}$compartment. If minority populations are responsible for imatinib resistance, this is still likely to occur via BCR-ABL-independent mechanisms.

Imatinib inhibits $B C R-A B L$ in primitive, quiescent $C M L$ cells. CML stem cell quiescence is associated with imatinib resistance in vitro, leading to the hypothesis that the residual population of leukemia cells in imatinib-treated CML patients contains quiescent cells $(18,19)$. It is unclear whether BCR-ABL is inhibited in quiescent CML cells. To clarify this question, we analyzed BCR-ABL activity in imatinib-treated quiescent CML cells using Ki-67 negativity as marker of quiescence (37). We sorted $\mathrm{Lin}^{-} \mathrm{Ki}-67^{-}$and 
A

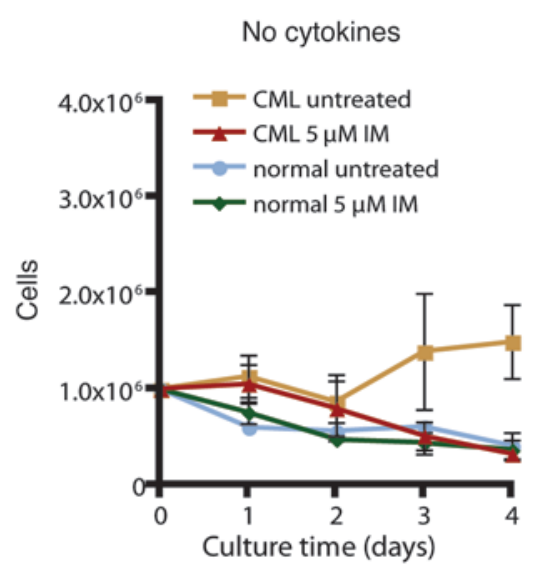

Cytokines:

SCF, FLT3 ligand,

GCSF, IL-3, IL-6

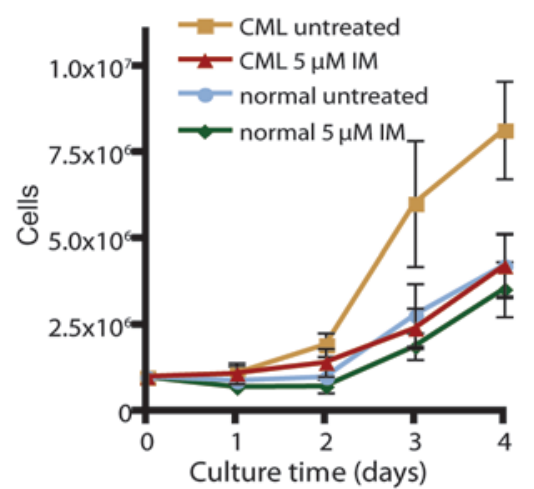

C
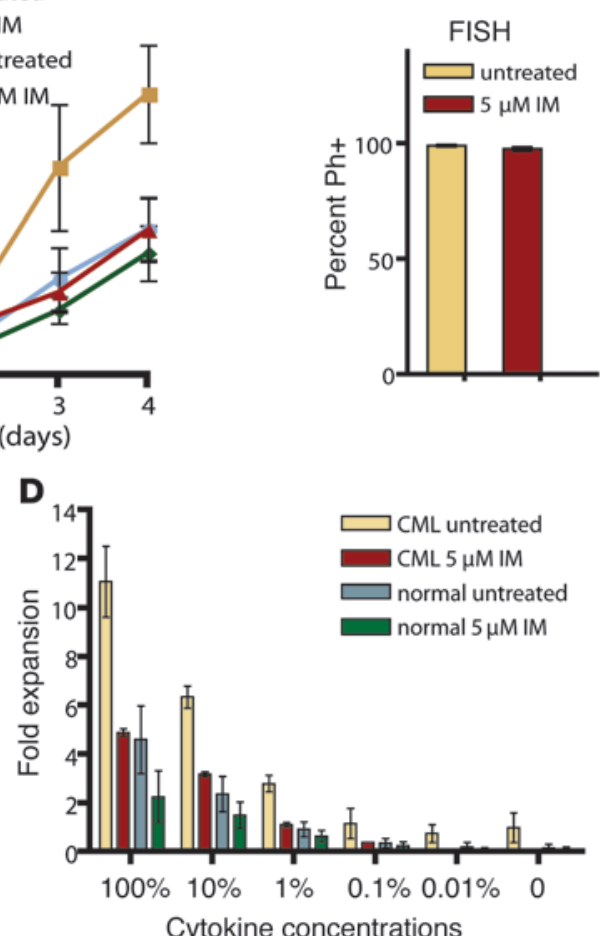

Cytokine concentrations
B

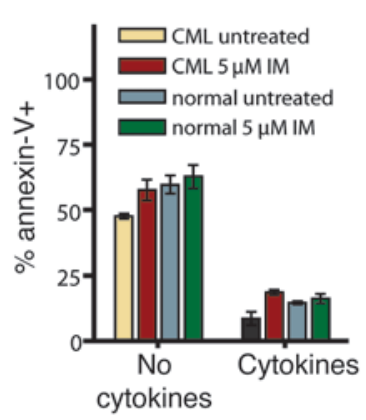

Apoptosis

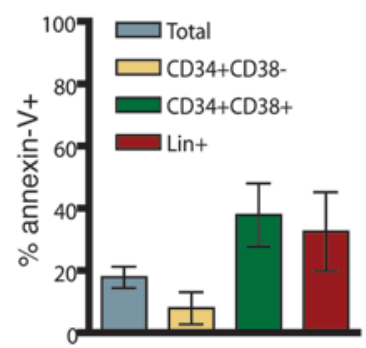

\section{Figure 4}

Proliferation and survival of CML progenitor cells in short-term imatinib culture. (A) Cell numbers of newly diagnosed CML or normal Lin- cells with or without imatinib were monitored daily during a 4-day culture in the absence of cytokines or in the presence of a cytokine cocktail that included SCF, FLT3 ligand, GCSF, IL-3, and IL-6. Normalized cell counts (mean \pm SEM) are plotted for CML $(n=10)$ and normal $(n=6)$ cells treated or not with $5 \mu \mathrm{M}$ imatinib. (B) Apoptosis in untreated versus imatinib cultures was evaluated by annexin-V staining $(n=3$, CML and normal). Mean \pm SEM on day 4 is shown for cultures with no cytokines and the 5-cytokine cocktail. Moreover, imatinib-treated CML cells costained with annexin-V, Lin cocktail, CD34, and CD38 on day $4(n=3)$ showed differing apoptosis frequencies in different cell types. (C) Percent BCR-ABL ${ }^{+}$cells were determined by FISH following culture with or without $5 \mu \mathrm{M}$ imatinib. (D) Fold expansion of $\operatorname{Lin}^{-}$cells $(n=3$, CML and normal) with or without imatinib was evaluated following a 4-day culture in a cytokine cocktail that was serially diluted relative to the conditions in A. Error bars represent SEM.

Lin-Ki- $67^{+}$cells from 2 patients with newly diagnosed chronic phase CML cultured for 4 hours in the presence or absence of $5 \mu \mathrm{M}$ imatinib (Figure $3 \mathrm{~A}$ ). To confirm tight selection of quiescent versus cycling cells, we additionally analyzed Ki-67 and PCNA expression by immunoblot analysis of sorted cells. Cell fractions were either Ki-67-PCNA- (quiescent) or $\mathrm{Ki}^{-} 67^{+} \mathrm{PCNA}^{+}$(cycling), thus verifying successful separation according to cell cycle status (Figure 3B). Additionally, we confirmed that the 4-hour culture period in which imatinib treatment was performed did not alter the cell cycle status, as indicated by equivalent numbers of Ki- $67^{+}$ cells prior to and following the brief culture (Figure 3C). Previous studies identified imatinib-resistant quiescent CML cells using CFSE staining to detect cell division during culture. To verify that the Ki-67- cells evaluated in our experiments are equivalent to undivided, CFSEhi cells, we evaluated Ki-67 expression in imatinibtreated Lin- CML cells that remained resistant to cell division. We found that the majority (99\%) of undivided cells were Ki-67-, whereas cells having undergone cell division ( $\mathrm{CFSE}^{\mathrm{lo} / \mathrm{mod}}$ ) were predominantly Ki-67+ (96\%; Figure 3D). This indicated that expression of Ki-67 within the context of our assay did in fact correlate with cell division, and the $\mathrm{Ki}-67^{-}$population we evaluated is likely equivalent to previously identified imatinib-resistant CML quiescent stem cells. Phospho-CRKL immunoblots of the sorted quiescent and cycling cells showed equivalent inhibition of BCR-ABL activity in both fractions (Figure 3E). These data suggest that any innate resistance exhibited by quiescent leukemic cells is likely to be BCR-ABL independent.

Cytokine supplementation supports in vitro proliferation and differentiation of CML stem and progenitor cells despite continuous inbibition of $B C R-A B L$ by imatinib. Given that imatinib inhibited BCR-ABL activity in CML stem cells, committed progenitors, and quiescent progenitors, we evaluated how inhibition of BCR-ABL activity affects the capacity of these cell types to survive and proliferate. Previous studies indicated that CML CD $34^{+}$cells exhibit limited cytokine-independent growth that is inhibited by imatinib (19). In agreement with these data, we found that short-term in vitro proliferation of Lin $^{-}$CML cells in the absence of cytokines, serum, and stromal support depended entirely on BCR-ABL activity, with growth curves similar to those of normal cells cultured under identical conditions (Figure 4A). Although some CML cells survived 4-day culture in the presence of imatinib, the majority of the cells were apoptotic, as were normal cells under the same conditions (Figure 4B). There- 
A
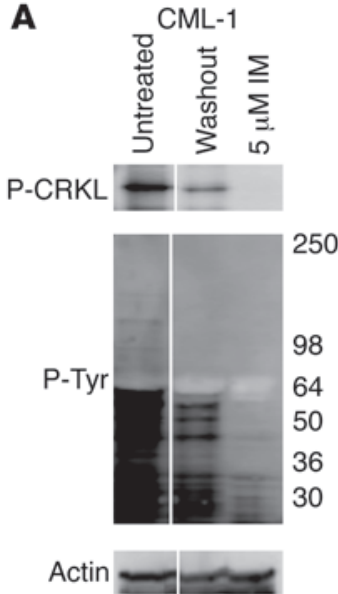

CML-2

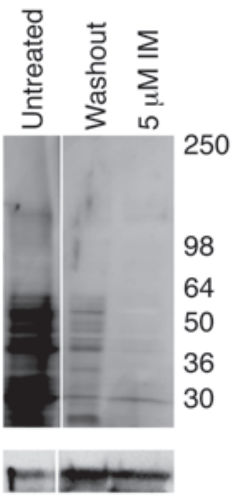

B

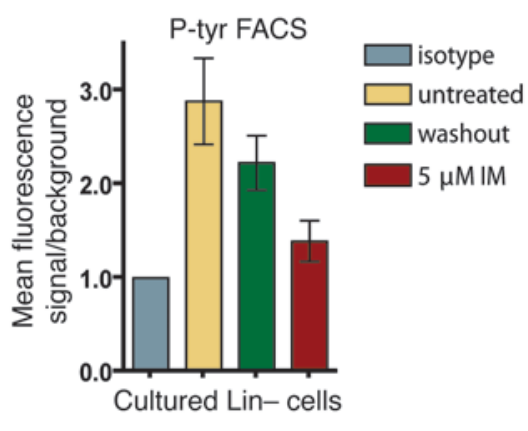

Figure 5

Inhibition of BCR-ABL activity in cultured CML Lin- cells. (A) Phospho-CRKL and total phosphotyrosine levels in bulk cultured Lin- cells were analyzed by immunoblot. Untreated cells, $5 \mu \mathrm{M}$ imatinibtreated cells in which imatinib was washed out then cultured without imatinib prior to immunoblots (washout), and cells treated continuously with $5 \mu \mathrm{M}$ imatinib are shown from a representative sample $(n=3)$. Lanes were run on the same gel but were noncontiguous (white lines). (B) Phosphotyrosine levels were analyzed by intracellular FACS analysis in bulk cultured Lin- cells. Matched isotype was used to establish background staining in each population. Graphs represent mean \pm SEM fluorescence signal relative to isotype control $(n=3)$.

fore, in the absence of external supportive factors, CML progenitors require BCR-ABL activity for cytokine-independent survival and proliferation and behave similarly to phenotypically matched normal controls upon inhibition of BCR-ABL.

We next evaluated proliferation of Lin' ${ }^{-}$CML cells from newly diagnosed patients during a 4-day culture period in the presence of a 5 -cytokine cocktail that included $100 \mathrm{ng} / \mathrm{ml} \mathrm{SCF}, 100 \mathrm{ng} / \mathrm{ml}$ FLT3 ligand, $20 \mathrm{ng} / \mathrm{ml} \mathrm{G-CSF}, 20 \mathrm{ng} / \mathrm{ml} \mathrm{IL-3}$, and $20 \mathrm{ng} / \mathrm{ml} \mathrm{IL-6.}$ CML cells demonstrated a proliferative advantage relative to normal cells that was suppressed by imatinib (Figure 4A). Untreated CML Lin ${ }^{-}$cells expanded 9.4-fold on average, while imatinib-treated CML cells and imatinib-treated normal cells expanded to the same degree (4.0-fold versus 4.8 -fold, $P=0.14$ ). Treatment with imatinib did not significantly inhibit expansion of normal cells $(P=0.3)$. Consistent with published data $(38,39)$, we observed only a modest increase in apoptosis in imatinib-treated cultures that was largely limited to $\mathrm{CD} 34^{+} \mathrm{CD} 38^{+}$and $\mathrm{Lin}^{+}$cells (Figure 4B). FISH for $B C R-A B L$ following the culture period demonstrated that in all samples, greater than $95 \%$ of cells were $\mathrm{Ph}^{+}$regardless of the presence of imatinib (Figure 4C), demonstrating that imatinib did not select normal progenitors.

Given that the concentrations of cytokines used in our assay were in excess of expected normal concentrations in the bone marrow, we serially diluted our initial cytokine cocktail to evaluate fold expansion of imatinib-treated CML Lin ${ }^{-}$cells and normal counterparts under more physiologically relevant conditions (approximately $0.1 \%-1 \%$ of initial cytokine concentrations). We found that in reduced cytokine conditions, imatinib-treated CML stem/progenitor cell survival was comparable to that of normal counterparts (Figure 4D). Overall, these data suggest that reversal of BCR-ABL-driven enhanced proliferation, rather than induction of apoptosis, directs the reduced ability of CML stem and progenitor cells to expand in the presence of imatinib and that even in the presence of physiologically relevant cytokine concentrations, ima-

A and $B$ ). Both assays showed that but largely restored upon removal (washout) of imatinib, indicating that BCR-ABL was inhibited in cells surviving and proliferating in the presence of imatinib. The reason for the moderate but reproducibly lower phospho-CRKL and phosphotyrosine levels in washout cells compared with cells from untreated cultures is unclear. Besides a technical explanation (e.g., incomplete washout), it could also reflect selection, during the culture period, of cells with lower BCR-ABL levels. Additionally, high-molecular weight tyrosine-phosphorylated proteins yielded a dim or absent signal. This is likely the result of technical issues, such as inefficient transfer of high-molecular weight proteins combined with small quantities of lysate available. Nonetheless, we confirmed continuous BCR-ABL inhibition by imatinib in CML progenitors throughout the 4-day imatinib culture. We conclude that BCR-ABL activity stimulates excessive growth or survival of CML progenitors relative to normal progenitors over a broad range of cytokine concentrations. Imatinib inhibition, however, appears to restore normal homeostatic properties, and thus cytokine supplementation bypasses the requirement for BCR-ABL activity for survival and proliferation of CML progenitors.

We next evaluated to what extent specific immunophenotypic subgroups contribute to BCR-ABL-independent cell expansion in our in vitro system. Immunophenotypic analysis of lineage-specific markers and CD34 and CD38 expression prior to and following the 4-day culture period demonstrated an overall reduction in the relative frequency of $\mathrm{Lin}^{-}$and $\mathrm{CD} 34^{+}$cells (Figure 6A), which indicates that the culture conditions permitted differentiation of both normal and CML cells independently of BCR-ABL activity. We observed a similar distribution of cell types in untreated versus imatinib-treated cultures, indicating that imatinib treatment did not select a subpopulation with innate resistance. Untreated CML cells showed enhanced expansion of both stem and progenitor cell compartments relative to normal 
A
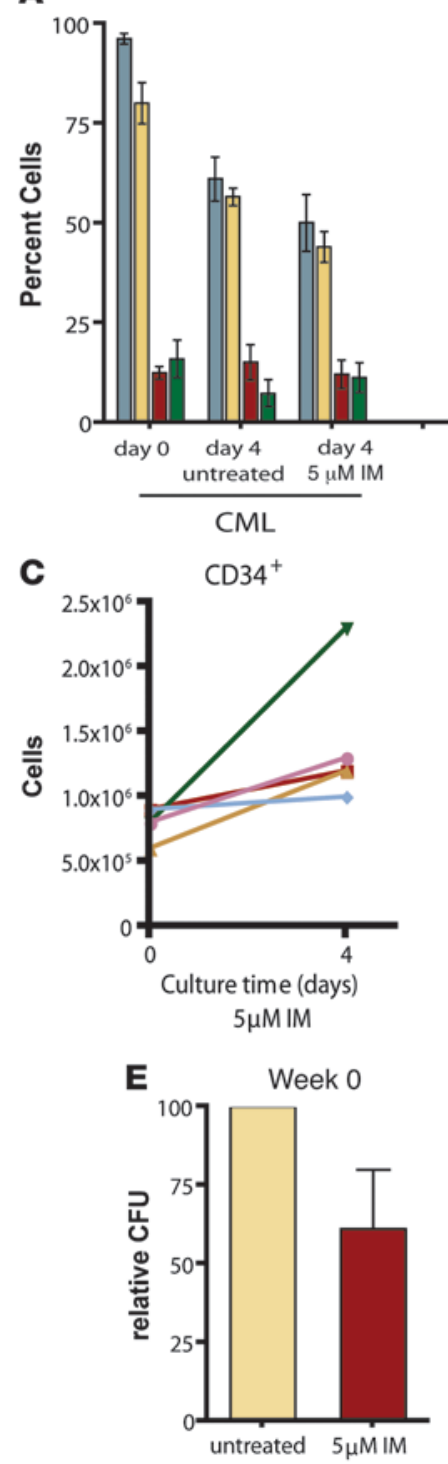

B

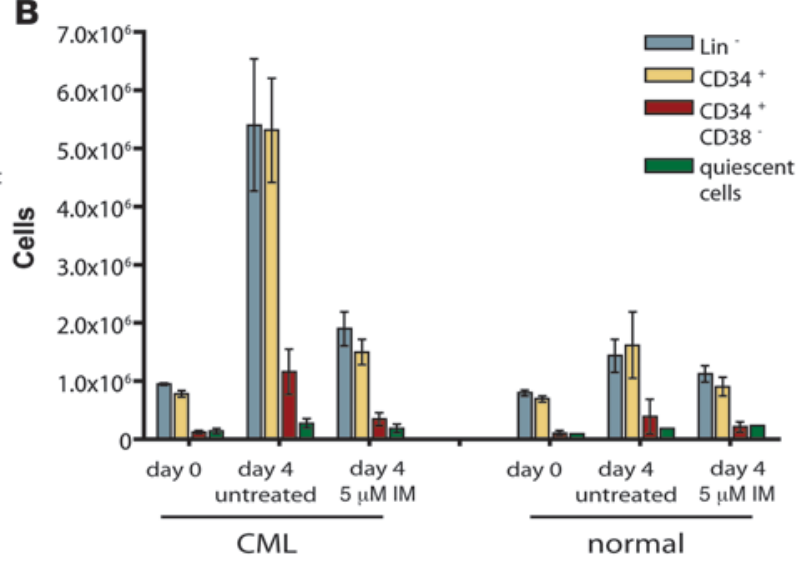

D

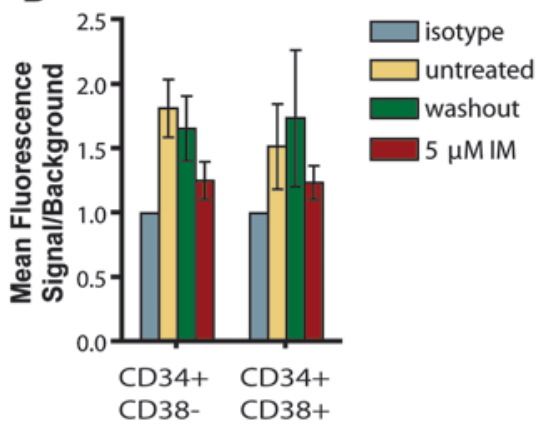

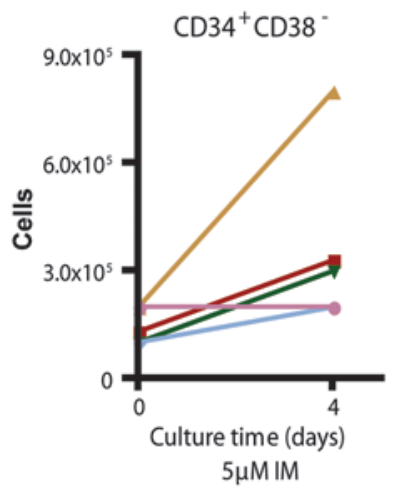

$\rightarrow-\mathrm{CML} 1$

$\simeq \mathrm{CML2}$

$\rightarrow \mathrm{CML3}$

$\rightarrow$ CML4

$\rightarrow$ CML5
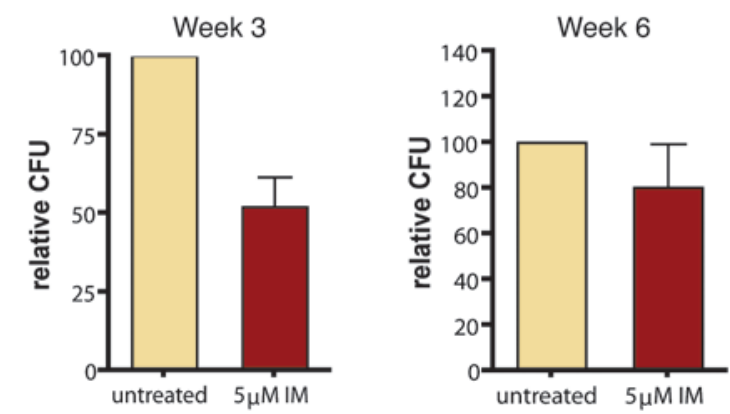

Figure 6

Survival and expansion of different CML stem and progenitor cell immunophenotypic and functional subtypes following culture with imatinib. (A) Relative frequencies of $\mathrm{Lin}^{-}, \mathrm{CD} 34^{+}, \mathrm{CD} 34^{+} \mathrm{CD} 38^{-}$, and quiescent cells prior to and following 4-day CML Lin- cell culture. Values are mean \pm SEM percent of total population ( $n=6$ [CML]; 3 [normal]). (B) Absolute cell numbers (normalized relative to starting cell density) of Lin ${ }^{-}, \mathrm{CD}^{2} 4^{+}$, and CD34+CD38-, and quiescent cells prior to and following culture with or without imatinib. Values are mean \pm SEM ( $n=6[$ CML]; 2 [normal]). (C) Expansion of $\mathrm{CD} 34^{+}$and CD34+CD38- CML cell numbers in the presence of imatinib shown for individual patient samples. (D) Phosphotyrosine levels were analyzed by intracellular FACS analysis in CD $34^{+} \mathrm{CD} 38^{-}$and $\mathrm{CD} 34^{+} \mathrm{CD} 38^{+}$cells following culture. Matched isotype was used to establish background staining in each population. Values are mean \pm SEM fluorescence signal relative to isotype control $(n=3)$. (E) Colonyforming and LTC-IC assays of postculture CML progenitors $(n=3)$ were performed. CFCs were evaluated at 0,3 , and 6 weeks of culture on murine stromal cells. Mean \pm SEM CFC numbers are shown as percent of untreated.

cells, which was normalized by imatinib inhibition of BCR-ABL. Interestingly, absolute numbers of $\mathrm{CD} 34^{+}$cells and $\mathrm{CD} 34^{+} \mathrm{CD} 38^{-}$ cells both increased in the presence of imatinib in all CML samples evaluated (Figure 6B); however, the samples showed variable degrees of expansion (Figure 6C). Given that there was a high frequency of differentiated $\left(\mathrm{Lin}^{+}\right)$cells following culture $(39 \% \pm 6 \%$ in the absence and $50 \% \pm 7 \%$ in the presence of imatinib), we reasoned that imatinib inhibition of BCR-ABL activity observed in bulk samples could reflect cells that had differentiated to an imatinib-sensitive stage. As this might obscure the identification of individual subpopulations of imatinib-insensitive progenitor cells maintaining BCR-ABL activity in the presence of imatinib, we analyzed phosphotyrosine levels in $\mathrm{CD}_{3} 4^{+}$and $\mathrm{CD} 34^{+} \mathrm{CD} 38^{-}$ cells that remained following imatinib treatment. As in the bulk culture, we found that phosphotyrosine levels in all subtypes were sensitive to imatinib (Figure 6D), consistent with continuous inhibition of BCR-ABL activity in CML stem and progenitor cells proliferating and differentiating in culture. 
A

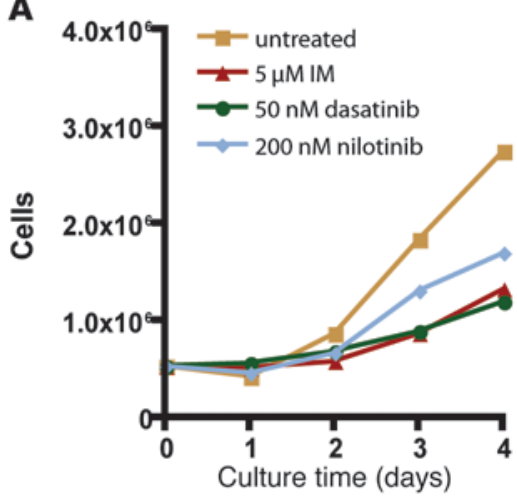

B

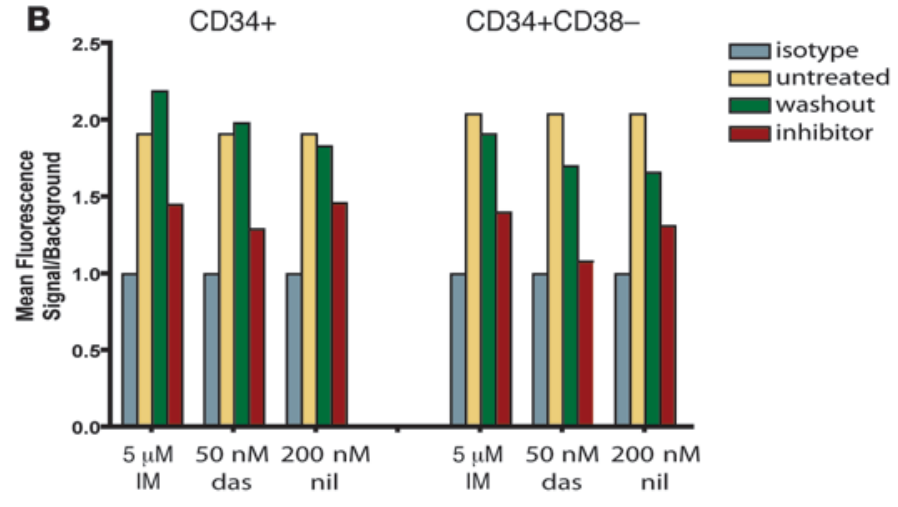

\section{Figure 7}

Sensitivity of CML stem and progenitor cells to imatinib, dasatinib, and nilotinib.(A) Lin- CML cells were cultured for 4 days with SCF, FLT3 ligand, GCSF, IL-3, and IL-6 in the presence of imatinib, dasatinib, and nilotinib. Daily cell counts were used to compare cell proliferation for each inhibitor. A representative sample is shown. (B) BCR-ABL activity following culture with imatinib, dasatinib (das), and nilotinib (nil) was determined by phosphotyrosine FACS in CD34+ and CD34+CD38- cells. Matched isotype was used to determine background levels. Mean fluorescence signal relative to background shown for a representative sample includes untreated cells, inhibitor-treated cells in which inhibitor was washed out prior to analysis (washout), and inhibitor-treated cells.

Since we observed BCR-ABL inhibition by imatinib in quiescent cells, we also sought to confirm findings from previous studies demonstrating their survival in imatinib culture. Using acridine orange staining, we identified quiescent cells capable of remaining quiescent despite the presence of cytokines. Although we observed quiescent cells in imatinib-treated cultures, imatinib treatment did not significantly enrich them, in contrast to previous reports $(19,27)$. In fact, the absolute number of quiescent cells following culture was the same in untreated and imatinib-treated cells (Figure 6, A and B).

To confirm that CML cells with the functional capacities of stem and progenitor cells were surviving culture with and without imatinib, we performed colony-forming assays and LTC-IC assays (40). Week 0 and week 3 colony-forming cells (CFCs), indicative of more and less primitive progenitor cells, respectively, were present following culture (Figure 6E). Absolute numbers of these cells were reduced by imatinib treatment, consistent with suppressed expansion of both $\mathrm{CD}_{3} 4^{+}$and $\mathrm{CD} 34^{+} \mathrm{CD} 38^{-}$cells upon BCR-ABL inhibition. Week 6 LTC-ICs, representing CML stem cells, were also present following culture with and without imatinib (Figure 6E). LTC-IC numbers were only slightly reduced by imatinib treatment and may represent a more quiescent population with a reduced proliferative capacity that minimizes the dramatic differences in expansion potential observed between treated and untreated progenitor cells. These results indicate that quiescent as well as proliferating primitive CML cells can survive imatinib inhibition of BCR-ABL and retain their primitive functional capacity. Taken together, our results indicate that imatinib inhibition of BCR-ABL restores normal homeostasis in all stem and progenitor cell subtypes rather than selecting for an innately resistant subset of cells while targeting the remainder.

$C M L$ stem and progenitor cells survive BCR-ABL inbibition by dasatinib and nilotinib. Given that in vitro survival and proliferation of CML stem and progenitor cells could occur in the absence of BCR-ABL kinase activity, we asked whether the more potent BCR-ABL inhibitors dasatinib and nilotinib exert effects similar to those of imatinib. Previous reports suggested that this was the case for nilotinib (41). Dasatinib appeared to improve growth suppression relative to imatinib, but failed to eradicate surviving quiescent cells (27).
During a 4-day culture in cytokine-enriched media, we observed inhibition of proliferation by nilotinib and dasatinib that was comparable to imatinib (Figure 7A). Additionally, dasatinib and nilotinib inhibited phosphotyrosine levels in $\mathrm{CD}^{+} 4^{+} \mathrm{CD} 38^{-}$and $\mathrm{CD} 34^{+} \mathrm{CD} 38^{+}$cells following in vitro culture (Figure 7B). These results confirmed that survival of CML stem and progenitor cells was BCR-ABL independent and suggest that disease persistence is likely to occur in patients treated with nilotinib or dasatinib.

\section{Discussion}

For many patients, imatinib transforms CML from a life-threatening disease into a chronic condition. Newly diagnosed patients with chronic phase CML have an almost $90 \%$ chance of being alive at 60 months after diagnosis (2). However, most patients continue to test positive by RT-PCR, and disease recurrence upon discontinuation of drug is the rule even in the minority of patients that become PCR undetectable (3-5). This indicates that CML stem cells survive in the presence of imatinib and suggests lifelong continuation of therapy, at considerable expense and sometimes despite significant side effects. Elucidating the mechanism by which persistent CML stem cells escape the effects of imatinib will be crucial for directing strategies to eradicate residual leukemia. The central question is whether disease persistence is BCR-ABL dependent, like many cases of resistance, or BCR-ABL independent. In the first scenario, overcoming persistence will require effectively targeting BCR-ABL in the relevant (stem) cell compartment. In the second scenario, treatment directed at BCR-ABL as a biochemical target will not eliminate CML stem cells, and disease eradication will require a fundamentally different approach. This issue has been widely debated, and much of the literature to date has presented conflicting results, due in part to technical difficulties that accompany attempts to study exceedingly small, poorly defined primary cell populations combined with the use of small sample numbers. We sought to comprehensively evaluate whether BCR-ABL activity is inhibited by imatinib in several primitive CML cell populations by using multiple complimentary methods, including immunoblotting, phospho-FACS, and immunocytochemistry, evaluating large sample numbers when possible and establishing rigorous 
A
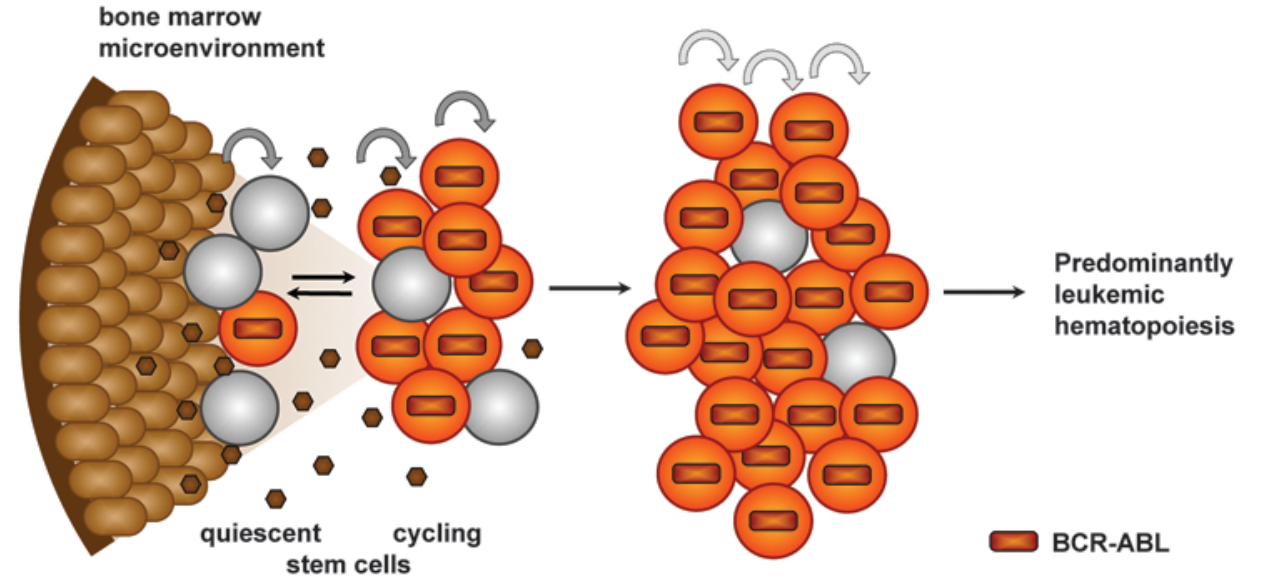

B

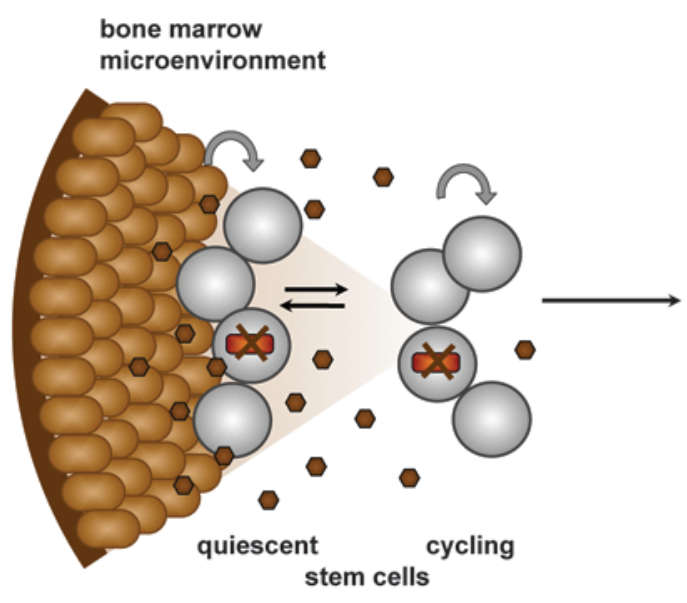

Figure 8

Model of CML disease persistence with imatinib treatment. Orange cells represent CML cells in a BCR-ABL-active state. Gray cells, which indicate lack of BCR-ABL activity, are either normal (nonleukemic) cells or CML cells in which BCR-ABL is suppressed by imatinib treatment. Brown cells represent stroma, and small dark brown circles are secreted cytokines. (A) BCR-ABL activity drives expansion of primitive CML cells. (B) Imatinib treatment inhibits BCR-ABL activity in CML stem cells, restoring normal homeostasis and eliminating the proliferative advantage of leukemic cells. Normal hematopoiesis is reestablished; however, the bone marrow microenvironment supports survival of CML stem cells that are not oncogene addicted. standards for negative controls to achieve reproducible results independent of the assay system. We analyzed the behavior both of populations attributed to disease persistence and of individual cells within those populations. Additionally, we examined the correlation between BCR-ABL inhibition by imatinib and survival and growth of these primitive populations to establish a model for how persistent CML cells may function in the context of treatment with imatinib and next-generation BCR-ABL inhibitors.

In a first set of experiments to determine whether CML stem cell survival is BCR-ABL dependent or independent, we used FACS sorting, intracellular staining, and immunoblot analysis to investigate phospho-CRKL and phosphotyrosine levels in CML stem and progenitor cells exposed to imatinib. In vitro imatinib treatment reduced phospho-CRKL and total phosphotyrosine levels in the $\mathrm{CD} 4^{+} \mathrm{CD} 38^{-}$and $\mathrm{CD} 133^{+}$stem cell compartments of newly diagnosed CML patients to the levels seen in normal controls. Importantly, the degree of BCR-ABL inhibition in CML stem cells was comparable to that of more mature $\mathrm{CD} 34^{+} \mathrm{CD} 38^{+}$cells and CMLderived cell lines, which indicated that BCR-ABL in the context of CML stem cells was not resistant to inhibition by imatinib.

Our findings are consistent with those of a study in which immunoblots of $\mathrm{CD} 34^{+} \mathrm{CD} 38^{-}$cells from a single CML patient showed a dose-dependent reduction of phospho-CRKL in response to ima- tinib (26), but they differ from those of Copland et al., who used phospho-CRKL flow cytometry as their principal technique to assay BCR-ABL activity (27). The reasons for the differing results are likely technical. Although phospho-CRKL flow cytometry presents a practical advantage over immunoblotting by permitting analysis of rare cell populations, in our hands, insufficient staining specificity in the context of primary cells posed a considerable challenge. We therefore chose to validate our results using phosphotyrosine flow cytometry and phospho-CRKL immunoblotting. Phosphotyrosine FACS analysis showed that imatinib treatment in CML stem and progenitor cells reduced signals to the levels seen in normal controls. However, by immunoblotting, we observed complete inhibition of phospho-CRKL in CML stem and progenitor cells after imatinib treatment. Thus, these data indicate that the residual signal detected by FACS is not the result of residual BCR-ABL kinase activity. We also observed the same consistent pattern of BCR-ABL inhibition by imatinib in CML stem and progenitor cells from multiple patients, consistent with adequate access of the drug to its biochemical target.

Total phosphotyrosine and phospho-CRKL as a substrate of BCR-ABL have been widely used as surrogate markers for BCR-ABL activity, largely because of the availability of highquality antibodies allowing consistent robust detection within 
the context of primary cells. Ideally, however, BCR-ABL activity would be measured directly. Although we attempted to expand our assays to include phospho-BCR-ABL and additional BCR-ABL substrates and downstream signaling components, we were limited technically by the utility of available antibodies. Because our methods of detection of phospho-CRKL or total phosphotyrosine yielded reproducible results that were well supported by appropriate negative controls, we ultimately favored the use of these surrogate markers.

We also explored how the inhibition of BCR-ABL activity in primitive CML cells affected their survival and proliferation. When high concentrations of exogenous cytokines were supplied, $\mathrm{Lin}^{-}, \mathrm{CD} 34^{+}$, and $\mathrm{CD} 34^{+} \mathrm{CD} 38^{-}$cells remained capable of in vitro proliferation despite continuous BCR-ABL inhibition. Imatinib reduced proliferation of all CML progenitor cell types to the level of normal progenitor cells over a range of cytokine concentrations, but induced only moderate apoptosis that was predominantly limited to cells with more mature immunophenotypes. Additionally, we used LTC-IC assays to confirm that cells surviving BCR-ABL inhibition retained the in vitro functional capacity of stem cells. Although it would be ideal to assay stem cells by measuring engraftment in immunocompromised mice, LTC-IC is a widely used surrogate assay to assess capacity for long-term survival. Together, the survival of CML cells with stem and progenitor cell phenotype and function and the restoration of normal homeostasis in the presence of imatinib indicate that primitive CML cells do not require BCR-ABL activity for survival when cytokines are present.

Phenotypic markers such as CD34, CD38, and CD133 are used to identify populations enriched for stem cell activity; however, it is known that these populations are not entirely homogenous in function. It is conceivable that smaller subpopulations exist within our phenotypically defined stem cell compartment that are resistant to imatinib therapy and responsible for disease persistence. The mechanisms of imatinib resistance in smaller subpopulations could be BCR-ABL independent, as we observed for the population as a whole, and thus a subgroup with reactivated BCR-ABL in the presence of imatinib could be selected by extended imatinib treatment. However, the absence of better immunological markers of stemness or markers that define the persistent leukemic population has been a major obstacle to resolving this possibility. To address this, at least in part, we used immunocytochemistry of phospho-CRKL, phospho-STAT5, and phospho-AKT to evaluate BCR-ABL activity in individual cells within the CD34 ${ }^{+} \mathrm{CD} 38^{-}$population. We also tried to confirm our results using anti-phosphoc-ABL (Tyr245; Cell Signaling), which was used previously to detect phospho-c-ABL by FACS (42). However, in our hands, this antibody produced unreliable FACS results due to a low signalto-noise ratio, and on immunocytochemistry failed to detect any signal even at a very low (1:5) dilution. Therefore, we focused our analysis on other surrogate markers of BCR-ABL kinase activity, including phospho-CRKL, phospho-STAT5, and phospho-AKT. We observed that inhibition of BCR-ABL was homogeneous throughout the population, and we did not identify cells that demonstrated reactivated BCR-ABL activity in the presence of imatinib. Interestingly, phospho-AKT levels were low in $\mathrm{CD}^{+} 4^{+} \mathrm{CD} 38^{-}$ cells compared with the more mature $\mathrm{CD} 34^{+} \mathrm{CD} 38^{+}$cells and were not influenced by imatinib (Figure 2D). This was in concordance with a recent report on FOXO transcription factors in the same cell populations, in which the authors demonstrate that FOXO proteins are nuclear in $\mathrm{CD} 34^{+} \mathrm{CD} 38^{-} \mathrm{CML}$ cells and leukemia-ini- tiating cells, despite the presence of active BCR-ABL, in contrast to their cytoplasmic localization in more mature cells (36). Because AKT is the major kinase that phosphorylates FOXO1, 3A, and 4, this suggests that AKT activity is low in the most primitive cells. Mechanistically, this was shown to be the result of TGF- $\beta$ signaling that counteracts AKT in leukemia-initiating cells, consistent with our immunocytochemistry results. Together, our data support the notion that CML cells surviving imatinib therapy do so independently of BCR-ABL activity and in a uniform fashion.

There is considerable evidence that drug transport proteins display altered expression patterns in both normal and CML stem cells relative to more committed progenitors $(8,10,11)$, and it has been proposed that lower intracellular imatinib concentrations may lead to resistance. It remains controversial, however, whether imatinib is a substrate of potentially relevant transport proteins (43), and evidence that altered expression of efflux/influx proteins affects imatinib sensitivity in CML stem cells is lacking. We demonstrated that BCR-ABL activity was inhibited equivalently in CML stem and progenitor cells over a range of imatinib concentrations, which suggests that imatinib has access to the relevant target in CML stem cells, and factors other than insufficient intracellular imatinib caused by altered drug efflux/influx in CML stem cells must therefore be responsible for its limited efficacy in this population. In line with this, Copland et al. demonstrated equivalent uptake of imatinib in $\mathrm{CD} 34^{+} \mathrm{CD} 38^{-}$stem cells versus total $\mathrm{CD} 4^{+}$cells $(27)$, indicating that drug transport-mediated alteration of intracellular imatinib is an unlikely cause of resistance in the former population. Similarly, although BCR-ABL expression may be higher in primitive CML cells compared with progenitors, our data showed that BCR-ABL kinase activity was inhibited equally in $\mathrm{CML} \mathrm{CD} 34^{+} \mathrm{CD} 38^{+}$and $\mathrm{CD} 34^{+} \mathrm{CD} 38^{-}$cell populations, which rules out the possibility that kinase activity is sustained by high protein levels.

Stem cell quiescence has been proposed as a potential mechanism by which primitive leukemic cells escape the cytotoxic effects of imatinib, although no mechanistic link has been provided. In particular, it was unclear whether BCR-ABL activity mediated survival of this cell population. In accord with previous reports (19), we observed that primitive noncycling BCR-ABL-positive cells survive in the presence of imatinib upon ex vivo culture of CML cells from newly diagnosed patients. Moreover, using Ki-67 and PCNA as markers for cycling cells, we found that imatinib inhibited BCR-ABL in the quiescent population to a similar degree as in the cycling cells. This indicates that the ability of quiescent cells to survive in the presence of imatinib does not depend on BCR-ABL activity. The requirement of excessively large cell numbers for our analysis restricted us to the evaluation of BCR-ABL activity in Lin ${ }^{-}$ Ki-67- cells, rather than $\mathrm{Lin}^{-} \mathrm{CD} 34^{+} \mathrm{CD} 38^{-} \mathrm{Ki}^{-}{ }^{-67^{-}}$cells, a phenotypic subgroup that would be more representative of a true quiescent stem cell population. Thus, we cannot exclude that the BCR-ABL activity and imatinib sensitivity we observed in quiescent $\mathrm{Lin}^{-}$cells would differ in more primitive quiescent cells.

It remains unclear how the pro-proliferative effect of BCR-ABL affects quiescent CML stem cells. Expression of BCR-ABL was previously shown to increase the relative frequency of proliferating CML stem cells; however, Holyoake et al. identified a quiescent CML stem cell population that remained resistant to cycling despite expression of BCR-ABL or addition of cytokines (18), which suggests that mechanisms governing induction of cycling of CML stem cells are complex and are, at least in part, indepen- 
dent of BCR-ABL signaling. Our observation of BCR-ABL activity within the quiescent progenitor population likewise suggests that the pro-proliferative signals generated by BCR-ABL are not sufficient to induce cycling in all quiescent CML cells and further supports the concept that imatinib inhibition of BCR-ABL may minimally affect this population.

Efforts to induce cycling in resistant quiescent stem cells are currently being explored as a means of sensitizing leukemic stem cells to imatinib $(39,44)$. This principle relies on the assumption that imatinib will cause cycling stem cells to either undergo apoptosis or irreversibly commit to differentiation without regenerating the leukemic stem cell pool. We found that with cytokine support, both quiescent and cycling primitive leukemic cells survived imatinib inhibition and, consistent with previous studies (38), imatinib did not induce apoptosis. The survival of both populations despite BCR-ABL inhibition implies that driving quiescent CML stem cells into cycle as a sole means of sensitization to imatinib-induced cell death may be insufficient for their elimination. Disease persistence may therefore occur via the concurrence of 2 properties of CML stem cells: (a) the ability of primitive leukemia cells to escape apoptosis, despite BCR-ABL inhibition (i.e., lack of oncogene addiction); and (b) the ability of CML stem cells to self-renew (Figure 8).

Together, our data suggest that in vivo CML stem cells use survival signals other than BCR-ABL kinase to maintain their viability in the presence of tyrosine kinase inhibitors. Most likely, these signals are provided by the microenvironment and modulate the biological outcomes of BCR-ABL inhibition, such as growth arrest and apoptosis. As there is no evidence to our knowledge that the ability of imatinib to bind to its biochemical target is under the control of extrinsic factors, our data indicate that persistence of CML stem cells must be independent of BCR-ABL activity. This notion has far-reaching implications for all therapies that biochemically target BCR-ABL, the prediction being that none of these therapies will be able to eliminate CML stem cells. Our observation that CML stem cells survived in vitro exposure to the second-line ABL kinase inhibitors nilotinib and dasatinib corroborates this notion. Previously, 2 studies of newly diagnosed chronic phase patients treated with nilotinib or dasatinib showed higher rates of CCRs and major molecular responses at 12 and 24 months compared with standard and high-dose imatinib; however, lowlevel disease persistence continued in almost all patients, and in those who had been on drug for 30 months, a complete molecular response (absence of detectable BCR-ABL transcripts) was seen in 2 of 30 receiving nilotinib and 0 of 23 receiving dasatinib $(45,46)$.

Nearly all patients undergoing imatinib treatment maintain a residual leukemic population; however, the amount of residual disease is exceedingly small relative to the restored normal hematopoietic cell populations. While this appears difficult to reconcile with our observation that CML stem cells treated with imatinib behaved similar to normal cells, this may be due to the fact that the stem cell population in many patients is predominantly $\mathrm{Ph}^{-}$, and thus prevention of expansion of the CML clone at the progenitor cell level by imatinib treatment restores this situation. Alternatively, it is possible that suppression of BCR-ABL by imatinib creates a dominantnegative situation, or that CML cells under imatinib suppression may be at a subtle disadvantage relative to normal cells that we are unable to detect in our in vitro studies but would be relevant over time in patients treated with imatinib. Additional studies to address such subtle differences in growth kinetics of normal versus imatinibtreated CML cells would be necessary to fully resolve this issue.
In conclusion, we showed that primitive CML cells are capable of BCR-ABL-independent survival, which suggests that CML stem cell elimination may require completely different strategies, such as targeting stem cell self-renewal or disrupting interactions with the microenvironment. Future research should include examination of specific cytokine or adhesion-mediated interactions within the bone marrow microenvironment that may provide critical support for leukemic stem cells, CML stem cell homing mechanisms, or pathways required for self-renewal of these cells. Alternatively, it may be possible to eliminate CML stem cells using BCR-ABL as an immunological rather than a biochemical target (47). Nonspecific immunotherapy with interferon- $\alpha$ may see a revival, based on anecdotal reports that some patients with prior interferon exposure remained RT-PCR negative for prolonged periods of time after discontinuation of imatinib (5). The demonstration of BCR-ABL inhibition by imatinib in primitive CML cells is an important step toward understanding how to approach persistent disease with the ultimate goal of leukemic stem cell eradication as a means to achieve a cure.

\section{Methods}

Purification of Lin' cells from CML samples. Bone marrow or leukapheresis from 10 newly diagnosed chronic phase CML patients was obtained from the Department Hematology and Oncology, Oregon Health and Science University, and from M.D. Anderson Cancer Center. All studies using human cells were reviewed and approved by the IRBs of Oregon Health and Science University and University of Texas M.D. Anderson Cancer Center. All patients signed an IRB-approved informed consent prior to their participation in the study. Bone marrow from 3 normal donors was purchased commercially (AllCells).

Mononuclear cells were isolated by centrifugation through a Ficoll gradient. Red blood cells were lysed with $1 \times \mathrm{ACK}\left(0.15 \mathrm{M} \mathrm{NH}_{4} \mathrm{Cl}, 10 \mathrm{mM} \mathrm{KHCO}_{3}\right.$, and $0.1 \mathrm{mM}$ EDTA). Stem and progenitor cells lacking the lineage-specific markers CD2, CD3, CD14, CD15, CD16, CD19, CD24, CD56, CD66b, IgE, and Glycophorin A were isolated with a CML debulking antibody cocktail (Stem Cell Technologies) and by negative selection on an immunomagnetic column according to the manufacturer's protocol. The purity of the resulting Lin ${ }^{-}$cells was determined by staining with a cocktail of lineage-specific antibodies CD2, CD3, CD14, CD15, CD16, CD19, CD24, CD56, CD66b, IgE, and Glycophorin A (Lin cocktail-FITC; BD) and flow cytometric evaluation on a FACSAria flow cytometer (BD).

In vitro culture of primary $\mathrm{Lin}^{-}$cells. $\mathrm{Lin}^{-}$cells were cultured at a starting density of $5 \times 10^{5}$ cells $/ \mathrm{ml}$ at $37^{\circ} \mathrm{C}, 5 \% \mathrm{CO}_{2}$, in a humidified incubator for 4 days in serum-free media consisting of IMDM supplemented with $20 \%$ BIT (Stem Cell Technologies), $40 \mu \mathrm{g} / \mathrm{ml}$ low-density lipoprotein (Sigma-Aldrich), and $10^{-6} \mathrm{M} \beta$-mercaptoethanol. When specified, the following cytokines were included: $100 \mathrm{ng} / \mathrm{ml} \mathrm{SCF}$ (Stem Cell Technologies), $100 \mathrm{ng} / \mathrm{ml} \mathrm{G}-\mathrm{CSF}, 20 \mathrm{ng} / \mathrm{ml}$ FLT3 ligand, $20 \mathrm{ng} / \mathrm{ml} \mathrm{IL-3}$, and $20 \mathrm{ng} / \mathrm{ml}$ IL-6 (Sigma-Aldrich). Depending on the individual experiment, BCR-ABL inhibitors were added at approximately equipotent concentrations $(5 \mu \mathrm{M}$ imatinib, $50 \mathrm{nM}$ dasatinib, and $200 \mathrm{nM}$ nilotinib).

Immunophenotypic analysis, apoptosis, and quiescence of cultured Lin- cells. To analyze cell phenotype prior to and following culture, $10^{5}$ cells in PBS were stained with Lin cocktail-FITC, CD34-PE-Cy7 (BD), and CD38-PE-Cy5 (BD). To analyze apoptosis on day $4,2 \times 10^{5}$ cells cultured with and without imatinib were stained with annexin- $\mathrm{V}-\mathrm{PE}$ and 7 -aminoactinomycin $\mathrm{D}$ (7-AAD) using the Guava-Nexin kit according to the manufacturer's protocol and analyzed on a Guava cell counter (Guava Technologies). For analysis of quiescence on day 4, $2 \times 10^{5}$ cells were permeabilized with $0.067 \%$ Triton-X-100, $0.053 \mathrm{~N} \mathrm{HCl}$, and $0.1 \mathrm{M} \mathrm{NaCl}$ and then stained with $0.075 \mathrm{M}$ 
citric acid, $0.15 \mathrm{M} \mathrm{Na}_{2} \mathrm{HPO}_{4}, 0.11 \mathrm{M} \mathrm{NaCl}, 0.75 \mathrm{mM}$ EDTA, and $15 \mathrm{mM}$ Acridine Orange (Sigma-Aldrich) for 5 minutes at $4^{\circ} \mathrm{C}$. Cellular DNA and RNA content were analyzed on a FACSAria flow cytometer (BD).

FISH for BCR-ABL. Following culture, $10^{4}$ cells from each condition were washed with PBS and spotted onto polylysine-coated cytospin slides and dried. Cells were fixed in methanol/acetic acid and probed with dualcolor, dual-fusion BCR-ABL LSI probes (Abbott Molecular). 100 cells were screened for the presence of $\mathrm{Ph}$.

$B C R-A B L$ activity in cultured Lin $^{-}$cells. Following 4-day culture, $10^{6}$ untreated and imatinib-treated cells were incubated for 16 hours in serum-free media without cytokines to minimize background phosphotyrosine levels. Cells from the 4-day imatinib culture were washed twice with IMDM, incubated at $37^{\circ} \mathrm{C}$ in IMDM for 30 minutes, and then washed a third time to remove traces of imatinib. The culture was divided, and imatinib was either left out (washout) or added back in (postculture drug treatment) as a comparison to the imatinib-naive culture. Postculture drug treatment was carried out for 4 hours. Cells were lysed by boiling in 1XGS gel loading buffer and immunoblotted for phospho-CRKL (Tyr207) (Stem Cell Technologies), phosphotyrosine, 4G10 (Upstate Biotech), and actin (Calbiochem) as a loading control.

$B C R-A B L$ activity in FACS-gated subpopulations. Lin ${ }^{-}$cells were evaluated by FACS for phosphotyrosine content in the presence or absence of $5 \mu \mathrm{M}$ imatinib prior to and following in vitro culture. Following culture, cells were additionally incubated for 16 hours in serum-free media without cytokines to minimize background phosphotyrosine levels prior to staining. Cells that had been cultured in the presence of imatinib were washed as described above. The culture was divided, and imatinib was either left out (washout) or added back in as a comparison to the imatinib-naive culture. $10^{5} \mathrm{cells}$ per condition were treated with drug for 4 hours, then stained at $37^{\circ} \mathrm{C}$ with CD34-PE-Cy7 and CD38-PE-Cy5 or CD133-PE (Miltenyi). Cells were fixed and washed using saponin-based reagents according to the manufacturer's protocol (BD). Phosphotyrosine staining was done at $4{ }^{\circ} \mathrm{C}$ for 30 minutes using $50 \mathrm{ng}$ 4G10-FITC (Upstate Biotech) or matched isotype control. Phosphotyrosine MFI in cellular subpopulations was measured on a FACSAria. All data are reported as $\mathrm{MFI}_{\text {sample }} / \mathrm{MFI}_{\text {isotype }}$. BCR-ABL-expressing cell lines Mo7eBCR-ABL, Kcl22, and Lama were cultured in RPMI without serum for 16 hours prior to 4 -hour treatment with $5 \mu \mathrm{M}$ imatinib. Phosphotyrosine FACS staining was performed as described above. Alternatively, untreated and imatinib-treated lysates were immunoblotted with the phosphotyrosine antibody 4G10 (Upstate Biotechnology).

$B C R-A B L$ activity and imatinib sensitivity in sorted $C D 34^{+} C D 38^{+}$and $C D 34^{+} \mathrm{CD} 38^{-}$cells. Lin $^{-}$cells from $2 \mathrm{CML}$ leukaphereses were sorted using a FACSAria into $\mathrm{CD} 34^{+} \mathrm{CD} 38^{-}$and $\mathrm{CD} 34^{+} \mathrm{CD} 38^{+}$subpopulations using staining procedures described above. Sorted cells were divided into 2 culture conditions, untreated and $5 \mu \mathrm{M}$ imatinib, and incubated at $37^{\circ} \mathrm{C}$ in serum-free media for 4 hours. Sorted subpopulations with or without imatinib were immunoblotted for phospho-CRKL (Tyr207) (Stem Cell Technologies) and actin (Calbiochem) as a loading control. CD34-selected normal cells were purchased from AllCells.

Immunocytochemistry. Immunostaining for phospho-CRKL, phospho-AKT, and phospho-STAT5 was performed using a rabbit anti-human polyclonal antibody against phospho-CRKL (Tyr207), phospho-AKT (Ser473), and phospho-STAT5 (Tyr694) (Cell Signaling). Rabbit IgG was used as an isotype control in place of the primary antibodies. Briefly, cytospins from imatinibtreated or untreated $\mathrm{CD} 34^{+} \mathrm{CD} 38^{+}$and $\mathrm{CD} 34^{+} \mathrm{CD} 38^{-}$cells were fixed in $10 \%$ formalin for 10 minutes. After rinsing with PBS, cells were permeabilized in $100 \%$ methanol for 10 minutes and rehydrated in PBS for 10 minutes. Endogenous peroxidase and nonspecific background staining were blocked by incubating slides with $3 \%$ hydrogen peroxide for 10 minutes. After rinsing with PBS for 5 minutes, slides were blocked with $2.5 \%$ normal horse serum for 1 hour, followed by incubation with the primary antibodies, at 1:50 dilution for overnight at room temperature. After rinsing with PBS containing 0.1\% Tween-20 for 5 minutes, slides were incubated with anti-rabbit Ig (ImmPRESS reagent peroxidase; Vector) for 60 minutes at room temperature and washed again with $0.1 \%$ Tween- 20 for 5 minutes. The slides were developed with DAB chromogen (Dako) for 3 minutes, and slides were washed with $\mathrm{H}_{2} \mathrm{O}$.

$B C R-A B L$ activity and imatinib sensitivity in sorted Ki-67 ${ }^{+}$and Ki-67- cells. Lin ${ }^{-}$ cells from 2 patients (not cultured) were sorted based on Ki-67 expression. Prior to staining, unsorted cells were incubated 4 hours with or without $5 \mu \mathrm{M}$ imatinib in serum-free media. Cells were fixed in $4^{\circ} \mathrm{C} 70 \%$ ethanol and stained with $\mathrm{Ki}-67-\mathrm{PE}(\mathrm{BD})$ or matched isotype control according to the manufacturer's instructions. $\mathrm{Ki}-67^{-}$and $\mathrm{Ki}-67^{+}$subpopulations were isolated using FACSAria. All steps, including the sort, were performed at $4^{\circ} \mathrm{C}$ to minimize phosphatase activity. Sort purity was confirmed by FACS analysis and immunoblotting of sorted cell lysates for Ki-67 (Santa Cruz Biotechnology) and PCNA (Stem Cell Technologies), markers expressed exclusively in cycling cells. To assess BCR-ABL activity, lysates from sorted subpopulations with or without imatinib treatment were immunoblotted for phospho-CRKL and actin as a loading control. To verify that Ki-67- cells failed to undergo cell division in culture, Lin $^{-}$cells were stained with $100 \mathrm{nM}$ CFSE (Sigma-Aldrich), then cultured in serum-free media for 72 hours in the presence of imatinib. Following culture, cells were stained with Ki-67-PE, and the frequency of Ki- $67^{+}$and Ki-67- cells within the CFSE (undivided) and CFSE ${ }^{\mathrm{lo} / \mathrm{mod}}$ subpopulations was evaluated. Gating of undivided cells was established with a control culture that included $100 \mathrm{nM}$ colcemid.

LTC-IC assays of cultured Lin ${ }^{-}$CML cells. Murine stromal M210B 4 cells plated at $5 \times 10^{4}$ cells/well in a 24 -well format were irradiated with $40 \mathrm{~Gy} .10^{5}$ postculture Lin- CML cells $(n=3)$ treated or not with $5 \mu \mathrm{M}$ imatinib were cultured in triplicate wells in LTC-IC media (IMDM, horse serum, FBS, hydrocortisone). Immediately following culture, and at intervals of 3 weeks and 6 weeks, cells were detached with trypsin and plated in methylcellulose (Stem Cell Technologies). Colonies were counted following 14 days of culture, with greater than 50 cells per colony as the criteria for positive colony scoring. Individual colonies (10 per condition) were evaluated for the presence of $\mathrm{Ph}$ by FISH. CFC values were corrected to reflect the total $\mathrm{Ph}^{+} \mathrm{CFCs}$ present following the initial 4-day culture period with or without imatinib.

Statistics. All statistical analysis was performed using 1-tailed Student's $t$ test. A $P$ value less than 0.05 was considered statistically significant.

\section{Acknowledgments}

We thank Chris Koontz and Sarah Bowden for administrative support and Dorian LaTocha for help with FACS analysis. This manuscript is supported by the Leukemia and Lymphoma Society 7393-06: Specialized Center of Research (to B.J. Druker and M.W. Deininger), NHLBI grant HL082978-01 (to M.W. Deininger), Department of Defense grant CM050037 (to B.J. Druker and A.S. Corbin), and the T.J. Martell Foundation (to B.J. Druker). M.W. Deininger is a Scholar in Clinical Research of the Leukemia and Lymphoma Society. A. Agarwal is the recipient of a Lady Tata memorial trust award and the Knight Cancer Center Career Developmental award.

Received for publication March 24, 2008, and accepted in revised form October 27, 2010.

Address correspondence to: Michael W. Deininger or Brian J. Druker, OHSU Knight Cancer Institute, Oregon Health and Science University, 3181 SW Sam Jackson Park Rd. L592, Portland, Oregon 97293, USA. Phone: 503.494.1091; Fax: 503.494.3688; E-mail: deinginge@ohsu.edu (M.W. Deininger). Phone: 503.494.1288; Fax: 503.494.3688; E-mail: drukerb@ohsu.edu (B.J. Druker). 
1. Deininger MW, Goldman JM, Melo JV. The molecular biology of chronic myeloid leukemia. Blood. 2000;96(10):3343-3356.

2. Druker BJ, et al. Five-year follow-up of patients receiving imatinib for chronic myeloid leukemia. NEngl J Med. 2006;355(23):2408-2417.

3. Hughes TP, et al. Frequency of major molecular responses to imatinib or interferon alfa plus cytarabine in newly diagnosed chronic myeloid leukemia. NEngl J Med. 2003;349(15):1423-1432.

4. Merante S, Orlandi E, Bernasconi P, Calatroni S, Boni M, Lazzarino M. Outcome of four patients with chronic myeloid leukemia after imatinib mesylate discontinuation. Haematologica. 2005; 90(7):979-981.

5. Rousselot $\mathrm{P}$, et al. Imatinib mesylate discontinuation in patients with chronic myelogenous leukemia in complete molecular remission for more than 2 years. Blood. 2007;109(1):58-60.

6. Bhatia R, et al. Persistence of malignant hematopoietic progenitors in chronic myelogenous leukemia patients in complete cytogenetic remission following imatinib mesylate treatment. Blood. 2003;101(12):4701-4707.

7. Chu S, et al. Detection of BCR-ABL kinase mutations in CD34+ cells from chronic myelogenous leukemia patients in complete cytogenetic remission on imatinib mesylate treatment. Blood. 2005; 105(5):2093-2098.

8. Jiang X, et al. Chronic myeloid leukemia stem cells possess multiple unique features of resistance to BCR-ABL targeted therapies. Lenkemia. 2007; 21(5):926-935.

9. Sherbenou DW, et al. Mutations of the BCR-ABLkinase domain occur in a minority of patients with stable complete cytogenetic response to imatinib. Lenkemia. 2007;21(3):489-493.

10. Zhou $\mathrm{S}$, et al. The ABC transporter Bcrp1/ABCG2 is expressed in a wide variety of stem cells and is a molecular determinant of the side-population phenotype. Nat Med. 2001;7(9):1028-1034.

11. Chaudhary PM, Roninson IB. Expression and activity of P-glycoprotein, a multidrug efflux pump, in human hematopoietic stem cells. Cell. 1991; 66(1):85-94.

12. Burger $H$, van Tol $H$, Boersma AW, Brok $M$, Wiemer EA, Stoter G, Nooter K. Imatinib mesylate (STI571) is a substrate for the breast cancer resistance protein (BCRP)/ABCG2 drug pump. Blood. 2004;104(9):2940-2942.

13. Illmer T, et al. P-glycoprotein-mediated drug efflux is a resistance mechanism of chronic myelogenous leukemia cells to treatment with imatinib mesylate. Lenkemia. 2004;18(3):401-408.

14. Mahon FX, et al. MDR1 gene overexpression confers resistance to imatinib mesylate in leukemia cell line models. Blood. 2003;101(6):2368-2373.

15. Brendel C, et al. Imatinib mesylate and nilotinib (AMN107) exhibit high-affinity interaction with ABCG 2 on primitive hematopoietic stem cells. Leukemia. 2007;21(6):1267-1275.

16. Thomas J, Wang L, Clark RE, Pirmohamed M.
Active transport of imatinib into and out of cells: implications for drug resistance. Blood. 2004; 104(12):3739-3745

17. Crossman LC, Druker BJ, Deininger MW, Pirmohamed M, Wang L, Clark RE. hOCT 1 and resistance to imatinib. Blood. 2005;106(3):1133-1134.

18. Holyoake T, Jiang X, Eaves C, Eaves A. Isolation of a highly quiescent subpopulation of primitive leukemic cells in chronic myeloid leukemia. Blood. 1999;94(6):2056-2064.

19. Graham SM, et al. Primitive, quiescent, Philadelphia-positive stem cells from patients with chronic myeloid leukemia are insensitive to STI571 in vitro. Blood. 2002;99(1):319-325.

20. Konopleva M, Andreeff M. Targeting the leukemia microenvironment. Curr Drug Targets. 2007; 8(6):685-701.

21. Sorel N, Bonnet ML, Guillier M, Guilhot F, Brizard A, Turhan AG. Evidence of ABL-kinase domain mutations in highly purified primitive stem cell populations of patients with chronic myelogenous leukemia. Biochem Biophys Res Commun. 2004;323(3):728-730.

22. Weisberg E, et al. Characterization of AMN107, a selective inhibitor of native and mutant Bcr-Abl. Cancer Cell. 2005;7(2):129-141.

23. Shah NP, Tran C, Lee FY, Chen P, Norris D, Sawyers CL. Overriding imatinib resistance with a novel ABL kinase inhibitor. Science. 2004;305(5682):399-401.

24. Gorre ME, et al. Clinical resistance to STI-571 cancer therapy caused by BCR-ABL gene mutation or amplification. Science. 2001;293(5531):876-880.

25. Chu S, Holtz M, Gupta M, Bhatia R. BCR/ABL kinase inhibition by imatinib mesylate enhances MAP kinase activity in chronic myelogenous leukemia CD34+ cells. Blood. 2004;103(8):3167-3174.

26. Konig H, et al. Enhanced BCR-ABL kinase inhibition does not result in increased inhibition of downstream signaling pathways or increased growth suppression in CML progenitors. Lenkemia. 2008; 22(4):748-755.

27. Copland M, et al. Dasatinib (BMS-354825) targets an earlier progenitor population than imatinib in primary CML but does not eliminate the quiescent fraction. Blood. 2006;107(11):4532-4539.

28. Bhatia M, Wang JC, Kapp U, Bonnet D, Dick JE. Purification of primitive human hematopoietic cells capable of repopulating immune-deficient mice. Proc Natl Acad Sci U S A. 1997;94(10):5320-5325.

29. Yin AH, et al. AC133, a novel marker for human hematopoietic stem and progenitor cells. Blood. 1997;90(12):5002-5012.

30. Gambacorti-Passerini $C$, et al. Inhibition of the $\mathrm{ABL}$ kinase activity blocks the proliferation of $\mathrm{BCR} / \mathrm{ABL}+$ leukemic cells and induces apoptosis. Blood Cells Mol Dis. 1997;23(3):380-394.

31. Cortes JE, et al. Phase III, randomized, open-label study of daily imatinib mesylate $400 \mathrm{mg}$ versus 800 $\mathrm{mg}$ in patients with newly diagnosed, previously untreated chronic myeloid leukemia in chronic phase using molecular end points: tyrosine kinase inhibitor optimization and selectivity study. J Clin Oncol. 2010;28(3):424-430.
32. Peng B, et al. Pharmacokinetics and pharmacodynamics of imatinib in a phase I trial with chronic myeloid leukemia patients. J Clin Oncol. 2004;22(5):935-942.

33. Shah NP, et al. Transient potent BCR-ABL inhibition is sufficient to commit chronic myeloid leukemia cells irreversibly to apoptosis. Cancer Cell. 2008;14(6):485-493.

34. Snead JL, et al. Acute dasatinib exposure commits Bcr-Abl-dependent cells to apoptosis. Blood. 2009; 114(16):3459-3463.

35. Hamilton A, et al. BCR-ABL activity and its response to drugs can be determined in CD34+ CML stem cells by CrkL phosphorylation status using flow cytometry. Leukemia. 2006;20(6):1035-1039.

36. Naka K, et al. TGF-beta-FOXO signalling maintains leukaemia-initiating cells in chronic myeloid leukaemia. Nature. 2010;463(7281):676-680.

37. Scholzen T, Gerdes J. The Ki- 67 protein: from the known and the unknown. J Cell Physiol. 2000; 182(3):311-322.

38. Holtz MS, Slovak ML, Zhang F, Sawyers CL, Forman SJ, Bhatia R. Imatinib mesylate (STI571) inhibits growth of primitive malignant progenitors in chronic myelogenous leukemia through reversal of abnormally increased proliferation. Blood. 2002;99(10):3792-3800.

39. Holtz M, Forman SJ, Bhatia R. Growth factor stimulation reduces residual quiescent chronic myelogenous leukemia progenitors remaining after imatinib treatment. Cancer Res. 2007;67(3):1113-1120.

40. Bock TA. Assay systems for hematopoietic stem and progenitor cells. Stem Cells. 1997;15 suppl 1:185-195.

41. Jorgensen HG, Allan EK, Jordanides NE, Mountford JC, Holyoake TL. Nilotinib exerts equipotent antiproliferative effects to imatinib and does not induce apoptosis in CD34+ CML cells. Blood. 2007;109(9):4016-4019.

42. Bandyopadhyay $\mathrm{G}$, et al. Chlorogenic acid inhibits Bcr-Abl tyrosine kinase and triggers p38 mitogenactivated protein kinase-dependent apoptosis in chronic myelogenous leukemic cells. Blood. 2004; 104(8):2514-2522.

43. Jordanides NE, Jorgensen HG, Holyoake TL, Mountford JC. Functional ABCG2 is overexpressed on primary CML CD34+ cells and is inhibited by imatinib mesylate. Blood. 2006;108(4):1370-1373.

44. Jorgensen HG, et al. Intermittent exposure of primitive quiescent chronic myeloid leukemia cells to granulocyte-colony stimulating factor in vitro promotes their elimination by imatinib mesylate. Clin Cancer Res. 2006;12(2):626-633.

45. Cortes JE, et al. Nilotinib as front-line treatment for patients with chronic myeloid leukemia in early chronic phase. J Clin Oncol. 2010;28(3):392-397.

46. Cortes JE, et al. Results of dasatinib therapy in patients with early chronic-phase chronic myeloid leukemia. J Clin Oncol. 2010;28(3):398-404.

47. Rojas JM, Knight K, Wang L, Clark RE. Clinical evaluation of BCR-ABL peptide immunisation in chronic myeloid leukaemia: results of the EPIC study. Lenkemia. 2007;21(11):2287-2295. 